\title{
Synthetic Transformations for the Valorization of Fatty Acid Derivatives
}

\author{
José M. Fraile \\ José I. García*a \\ Clara I. Herrerías \\ Elisabet Pires ${ }^{\mathrm{a}}$ \\ a Instituto de Síntesis Química y Catálisis Homogénea (ISQCH) y \\ Departamento de Química Orgánica. Universidad de \\ Zaragoza-CSIC. Facultad de Ciencias. Calle Pedro Cerbuna, 12 \\ E-50009 Zaragoza (Spain) \\ * indicates the main/corresponding author. \\ jig@unizar.es \\ Click here to insert a dedication
}

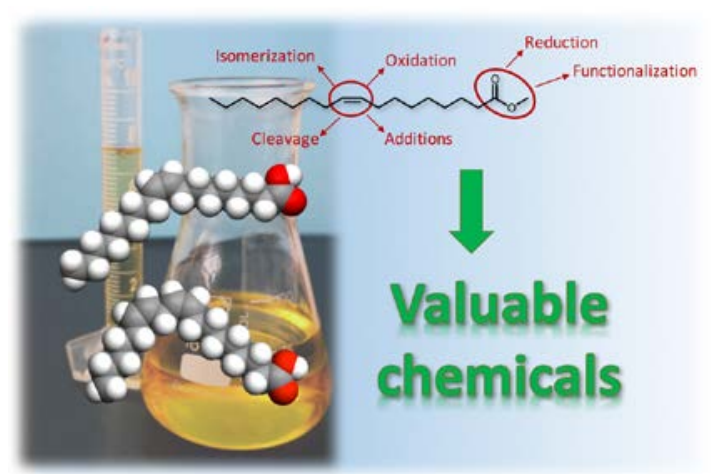

\section{Received
Accepted:}

Published online:

Abstract Oleochemistry is a growing field from the industrial point of view, and one of the basis for a more sustainable chemical production, less dependent of fossil sources. From this point of view, the development of selective and efficient synthetic transformations of triglycerides and fatty acids and esters is an active research field. This short review describes an overview of the most recent advances in the synthetic transformations of fatty acid derivatives into valuable chemicals.

1 Introduction

2 Triglycerides

2.1 Reactions on the ester group and multistep processes

2.2 Epoxidation

2.3 Ozonolysis

2.4 Cross metathesis

3 Reactions on the ester group of fatty acids and esters

3.1 Synthesis of free carboxylic acids

3.2 Synthesis of carboxylic esters

3.3 Reduction to alcohols and aldehydes

3.4 Synthesis of nitrogenated derivatives

4 Oxidation of Unsaturated Fatty acids and esters

4.1 Epoxidation and reactions of epoxides

4.2 Allylic oxidation

4.3 Synthesis of ketoderivatives

4.4 Oxidative cleavage

5 Addition reactions of unsaturated fatty acids and esters

5.1 Hydrogenation and hydroformilation

5.2 Cycloadditions and related reactions

5.3 Addition of carboxylic acids

5.4 Hydroalkylation

5.5 Radical additions

6 Other reactions of unsaturated fatty acids and esters

6.1 Cross metathesis

6.2 Isomerization

7 Conclusion and outlook

Key words Triglycerides; Vegetable oils; Fatty acids; Oleochemistry; Catalysis; Selectivity; Monomers; Chemicals from biomass

\section{Introduction}

The quest for sustainability in chemical and manufacturing industry is one of the defining features of $21^{\text {th }}$ century society.
Global challenges, such as climate change and depletion of fossil energy and raw materials resources must be addressed from a new perspective. Green Chemistry emerged at the end of the past century as an alternative to build a more sustainable world through a more sustainable chemistry. The twelve principles of Green Chemistry, formulated by Anastas and Warner have become a guide that has been quickly adopted both in academia and industry. This success is not due either to their revolutionary character or to their outstanding originality, but to the fact they gather and summarize a number of ideas and guidelines that have plenty of common sense.

One of these core ideas is that a sustainable chemistry should be based on sustainable raw materials, i.e., a renewable source of chemicals mainly coming from biomass. Although this is a perfectly reasonable principle, its effective application is not devoid of difficulties from a practical point of view. Current chemical industry is largely based on hydrocarbons coming from fossil sources (mainly petroleum, but also coal and natural gas). Hydrocarbons are highly reduced and low functionalized organic compounds that must be transformed into different platform molecules, capable to provide the commodities, fine chemicals and specialties on which our modern society stands. These chemical transformations are nowadays quite well tuned, and the associated technological investment thoroughly amortized in most cases, so the economical side of the petrochemical industry appears to be unbeatable. On the other hand, a biomass-based chemical industry must tackle with several problems that makes it difficult its setting up. One of them is the wide variety of chemical compounds that can be extracted more or less directly from biomass: sugars, fatty acids, amino acids and proteins, terpenes, etc. In many cases, these compounds appear as complex mixtures difficult to separate. Furthermore, from a chemical point of view, many of these biomass-based chemical platforms are multifunctional organic compounds, which makes it difficult their selective transformation into valuable compounds. 


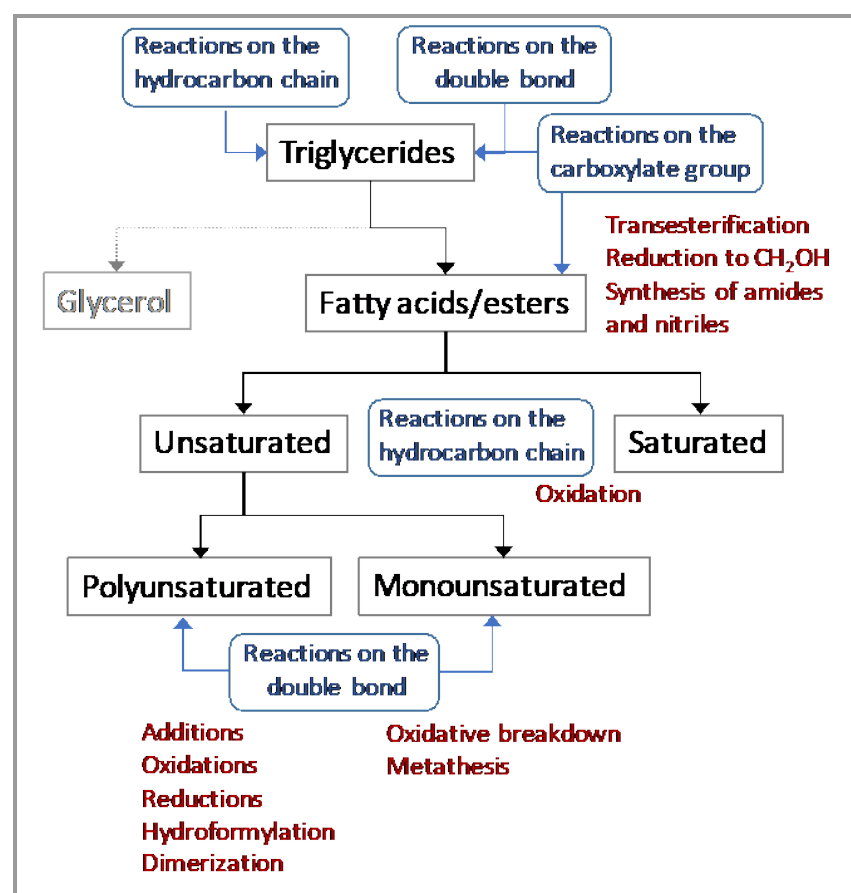

Figure 1 Synthetic transformations of fatty acids and esters covered in this review.

Despite these difficulties, it is unavoidable to address the synthetic challenge that the chemical transformation of biomass represents. In this context, at present fats and oils are the most important renewable feedstock processed in the chemical industry. ${ }^{1}$ The annual production of plant oils not employed to cover food needs is about 26 Mtons, which are used for biodiesel production (11 Mtons) and other industrial uses (15 Mtons) including oleochemical production. A number of reviews have been published, dealing with different kinds of biobased sources. ${ }^{1-4}$ In particular, glycerol and its derivatives have recently received a great deal of attention..$^{5-7}$ In this review we will focus on the other side of the oleochemical platform molecules, by summarizing the synthetic methods recently used to transform fatty acids and esters, mainly coming from vegetable oils. As there have been some previous reviews partially covering this topic, ${ }^{8,9}$ we will mainly focus on the most recent advances described in the literature having a synthetic interest. Figure 1 summarizes the main organization of the review, attending to the nature of the starting reagents and their corresponding transformation reactions.

\section{Triglycerides}

Although most of interesting synthetic transformations start from single fatty acids or esters, obtained after hydrolysis or transesterification of fats and oils, triglycerides can also be directly used as reagents. Figure 2 displays the possible sites subject to chemical transformation.

It must be noted that given the heterogeneous character of triglycerides coming from natural sources, many chemical transformations on these substrates lead to complex mixtures. This is not always a drawback, since these mixtures can often be used as such for practical applications. However, in this review we will consider as much as possible those synthetic transformations able to provide good yields of single, wellcharacterized products. This excludes, for instance, reactions at the allylic and bisallylic positions, which are not selective in general, as well as many transformations on the double bonds of unsaturated fatty acids, which leads to a wide distribution of possible products in the case of triglycerides of natural origin.

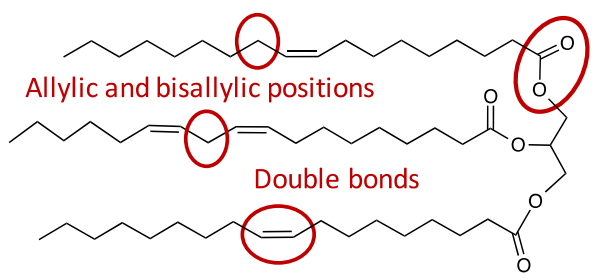

Figure 2 Sites on the triglyceride structure susceptible to chemical transformation.

\subsection{Reactions on the ester group and multistep processes}

Apart from hydrolysis or transesterification, ester groups of triglycerides can be reduced to different extent to give ethers and fatty alcohols. A procedure has been recently described to obtain 1-O-alkyl glycerol ethers from glycerides following a one-pot two-step procedure:10 transesterification followed by hydrogenation on $\mathrm{Pd} / \mathrm{C}$ with no intermediate purification (Scheme 1).

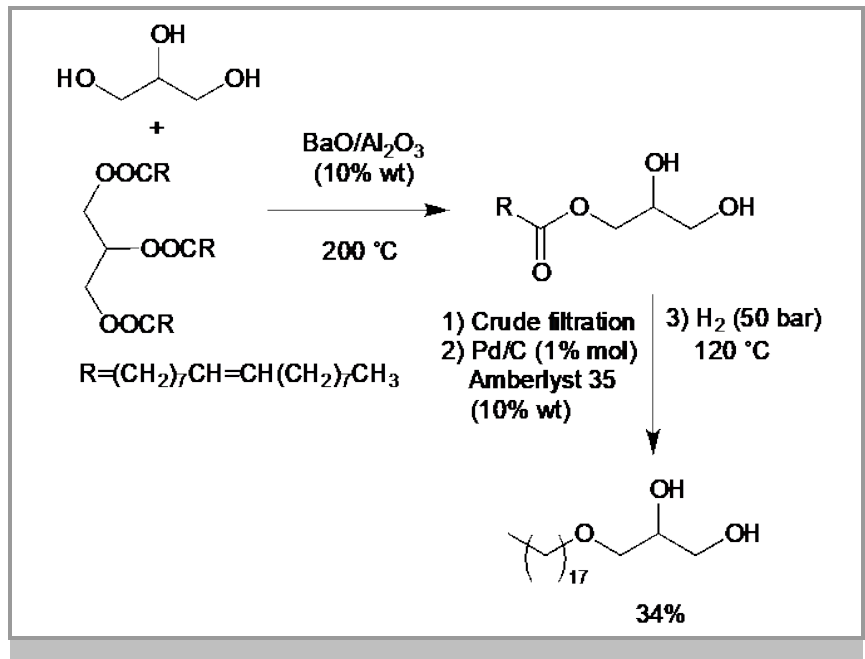

Scheme 1 One-pot synthesis of glycerol monoalkyl ethers from triglycerides.

When this protocol was applied to sunflower oleic refined oil ( $>90 \%$ triolein), pure 1- $O$-stearylglycerol monoether could be isolated in $34 \%$ overall yield. Another strategy to obtain triglyceride-derived ethers is the reduction with siloxanes, catalyzed by gallium salts (Scheme 2). In particular, a moderate $64 \%$ isolated yield has been described for the reduction of tributyrin with 1,1,3,3-tetramethyl-disiloxane (TMDS), catalyzed by $\mathrm{GaBr}_{3} .{ }^{11}$ With a larger triglyceride, like glyceryl triundec-10enoate, the isolated yield decreases to $44 \%$, keeping the integrity of the double bonds. 


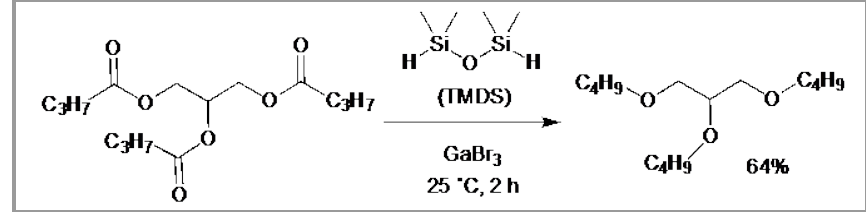

Scheme 2 Reduction of triglycerides to glycerol trialkyl ethers with a siloxane.

When the triglyceride ester groups are fully hydrogenated, fatty alcohols can be obtained. This has been accomplished using molecular hydrogen and different metal catalysts (Scheme 3). Thus, the use of the ruthenium complex of a tetradentate bipyridine ligand allows the hydrogenation of trilaurin and tristearin at 50 bar $\mathrm{H}_{2}$ and room temperature, leading to excellent isolated yields ( $>97 \%$ ) of the corresponding alcohols. ${ }^{12}$ Similarly, hydrogenation of triolein catalyzed by an osmium catalyst leads to an excellent $98 \%$ isolated yield of $(Z)$-octadec-9-en-1-ol (oleyl alcohol), which demonstrates the high selectivity of the catalyst towards ester hydrogenation, keeping the carbon-carbon double bonds unaltered. The same procedure has been applied to the hydrogenation of extra-virgin olive oil, leading to $90 \%$ isolated yield of a mixture of fatty alcohols, containing approximately $85 \%$ of oleyl alcohol. ${ }^{13}$ Very recently, a cobalt catalyst has been described, able to hydrogenate carboxylic esters and lactones to the corresponding alcohol. ${ }^{14}$ The hydrogenation of triolein at 100 ${ }^{\circ} \mathrm{C}$ and 80 bar $\mathrm{H}_{2}$ leads to $72 \%$ isolated yield of the fully reduced stearyl alcohol.

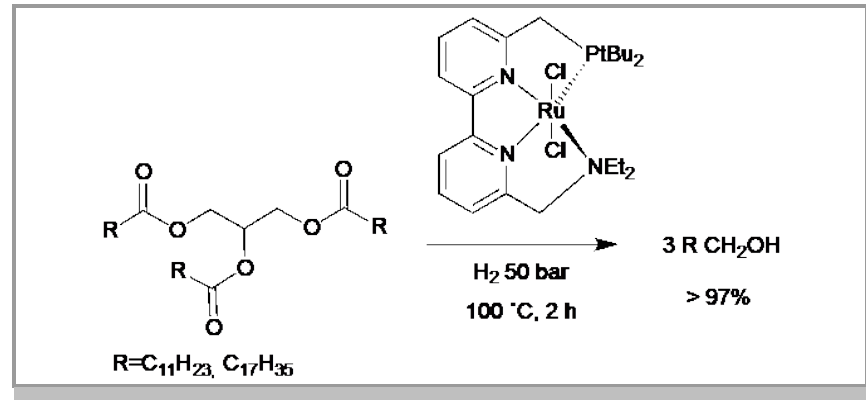

Scheme 3 Catalytic hydrogenation of triglycerides to fatty alcohols

Another procedure to obtain a fatty alcohol from the corresponding triglyceride has been described for castor oil (glyceryl triricinoleate). ${ }^{15}$ The authors of this work were studying the hydroboration-oxidation of ricinoleic acid ester derivatives. When the reaction on the triglyceride was carried out at room temperature, even with a great excess of borane, the double bond remained unreacted, but hydride reduction of the ester group took place, leading to the corresponding unsaturated diol with good yield (86\%) (Scheme 4). The effective hydroborationoxidation of the triglyceride required heating under reflux, to give a mixture of triols also in good isolated yield (85\%).

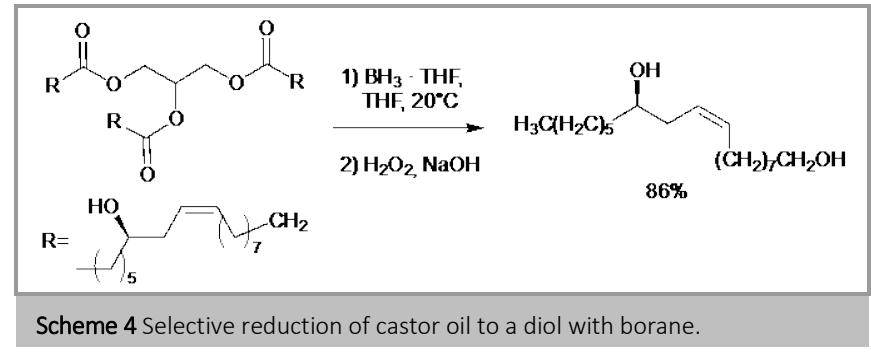

In a three-stage one-pot transesterification-isomerizationmethoxycarbonylation, high oleic sunflower oil was treated with $\mathrm{CO}$ (30 bar) and a catalytic system consisting of $\mathrm{Pd}(\mathrm{OAc})_{2}$, bis(ditert-butylphosphinomethyl)benzene and $\mathrm{CH}_{3} \mathrm{SO}_{3} \mathrm{H}$ to lead to $86 \%$ isolated yield of pure dimethyl nonadecanedioate, ${ }^{16}$ which can be subsequently reduced to the corresponding diol in mild conditions.

\subsection{Epoxidation}

Epoxidation of unsaturated triglycerides is a reaction industrially performed on a large scale, mainly using the performic acid procedure. Epoxidized triglycerides are used in formulations of lubricants, plastics, paints and dyes, in many cases after epoxide ring opening leading to polyol derivatives. An example of this methodology is the treatment of milkweed oil, rich in unsaturated fatty acids, to give polyhydroxytriglycerides or cinnamate estolides via epoxidation and ring opening (Scheme 5). ${ }^{17}$ As mentioned above, the use of a natural oil results in a mixture of different products. However, as these products are intended to be used as emulsifiers or sunscreens, there is no problem to work with the mixture. Up to $92 \%$ yield of epoxytriglycerides (determined through the difference of iodine values) from the refined milkweed oil can be obtained by this procedure. Concerning the cinnamate estolides, a pure fraction of the hexaferuloyl estolide ( $65 \%$ yield) can be isolated by vacuum liquid chromatography.

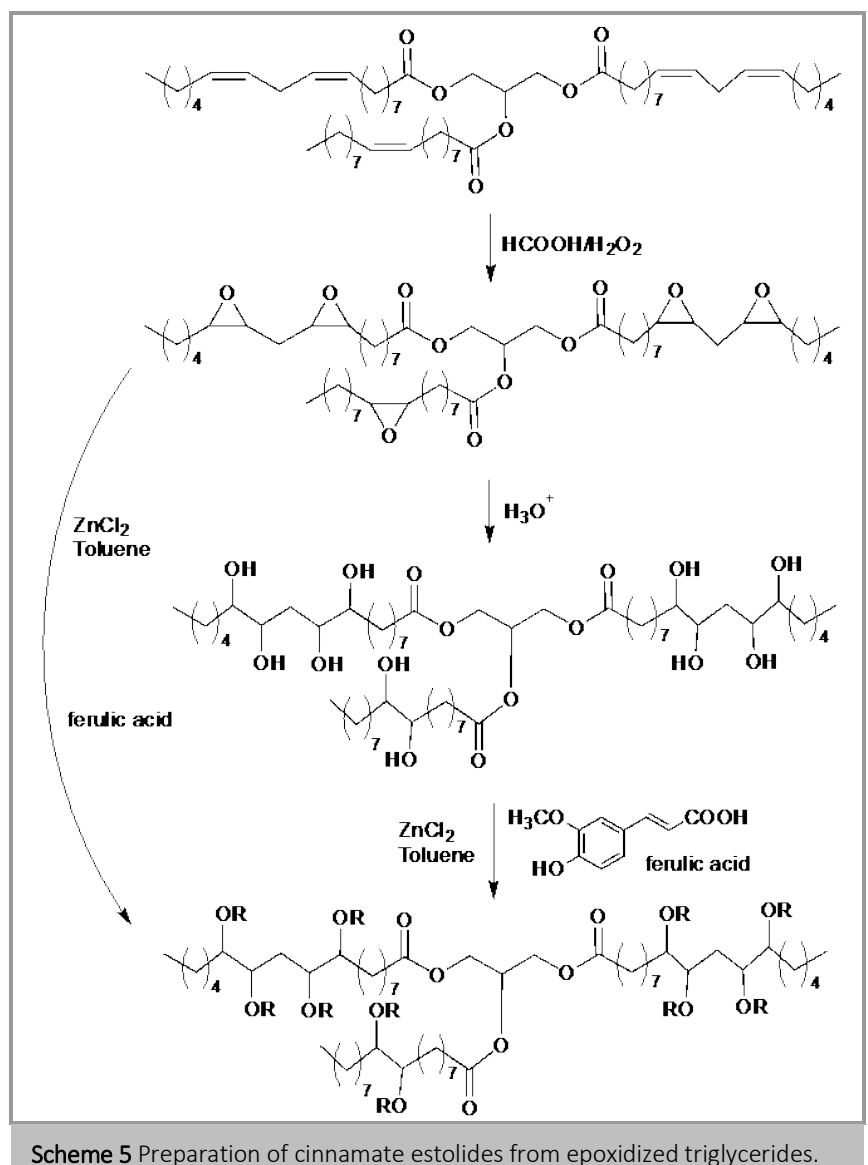

A similar strategy has been described for Osange orange seed oil whose composition is rich in unsaturated fatty acids (about $12 \%$ oleic acid and $76 \%$ linoleic acid). ${ }^{18}$ Quantitative amounts of 
the epoxidized triglycerides are obtained using peroxyformic acid generated in situ. The same procedure has been successfully applied to soybean, ${ }^{19}$ lineseed $^{20}$ and cottonseed oils. ${ }^{21}$ In fact, some epoxytriglyceride mixtures are already commercially available.

\subsection{Ozonolysis}

Oxidative cleavage of unsaturated triglycerides with ozone, combined with a subsequent reaction, provides interesting synthetic intermediates. Thus, the ozonolysis of castor oil in methanol at $-5{ }^{\circ} \mathrm{C}$, followed by addition of semicarbazide, leads to a mixture of two semicarbazones, coming from the two fragments of linoleic acid, isolated in $56 \%$ and $42 \%$ yield (Scheme 7). ${ }^{22} \mathrm{~A}$ slightly different synthetic scheme, using isopropanol at 0 ${ }^{\circ} \mathrm{C}$, allows obtaining up to $65 \%$ of the corresponding isopropyl $(R)$-3-hydroxynonanoate (Scheme 6). ${ }^{23}$ Finally the use of acetic acid instead of alcohols in similar reactions conditions leads to $(R)$-hydroxynonanoic acid in good yield (82\%).

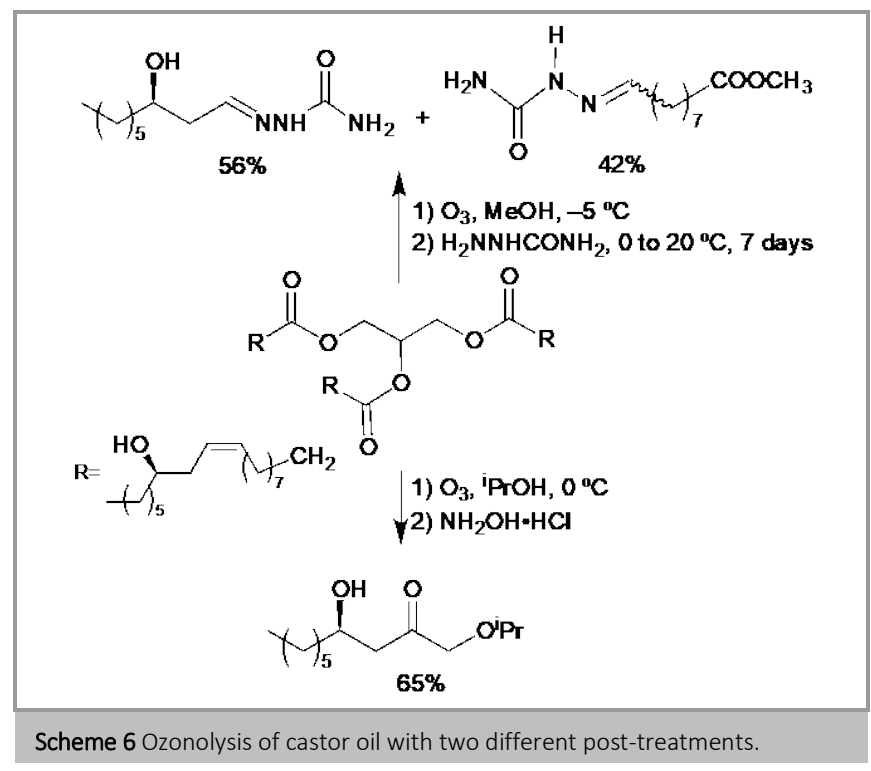

\subsection{Cross metathesis}

Another procedure to break down the double bonds of unsaturated triglycerides, leading to smaller triglycerides and alkenes, is cross metathesis. For instance, the reaction between 2-butene and triolein, promoted by second generation HoveydaGrubbs ruthenium catalysts (the so-called butenolysis), leads to a mixture of 2-undecene and the 9-undecenoate triglyceride with $>95 \%$ conversion (Scheme 7). ${ }^{24}$

The reaction is not stereoselective, so mixtures of $Z$ and $E$ alkenes are obtained, with predominance of the $E$ isomers. The resulting triglyceride can be easily transesterified with methanol to give methyl 9-undecenoate in good yields (93\% from high oleic sunflower seed oil). ${ }^{25}$ It is worth noting that in this case the heterogeneous composition of the natural oil is not a problem anymore, since most of unsaturated fatty acids being part of the triglycerides (oleic, linoleic, $\alpha$-linolenic, palmitoleic, etc.) are $\Delta^{9}$, so the butenolysis gives rise to the same product.

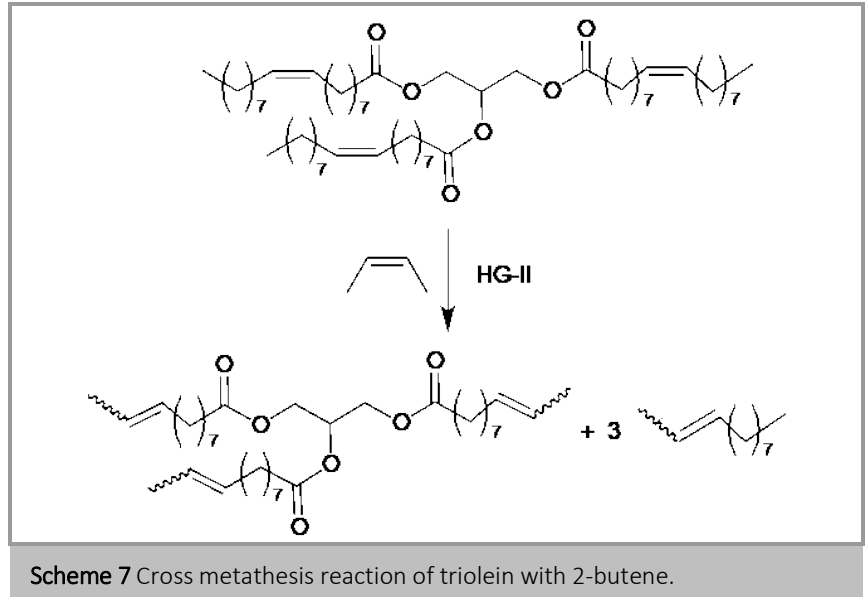

\section{Reactions on the ester group of fatty acids and esters}

Synthetic transformations of the carboxylic group of fatty acids and esters lead to an interesting variety of compounds bearing different functional groups, such as alcohols, amines, amides, nitriles, etc. Figure 3 summarizes these possible transformations, which will be examined in the next sections.

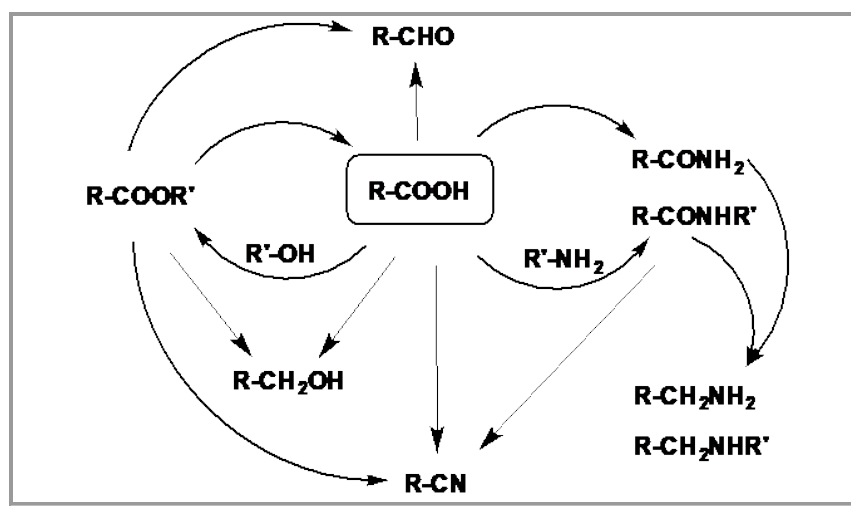

Figure 3 Possible synthetic transformations carried out on the carboxylate group of fatty acids and esters.

\subsection{Synthesis of free carboxylic acids}

Brønsted acids such as $\mathrm{HCl}$, promote catalytically the hydrolysis of fatty esters. ${ }^{26}$ In some cases, under organic/aqueous biphasic conditions used to avoid the reverse esterification, the Brønsted acid catalyst can be ineffective because of its high solubility in water. This problem has been overcome by using an oil-soluble hydrophobic Brønsted acid, $N, N$-diarylammonium pyrosulfate (Scheme 8). ${ }^{27}$ This acid catalyst is readily prepared by mixing equimolecular amounts of sulfuric acid and $N$-(2,4,6-triisopropylphenyl)- $N$-(2,6diphenylphenyl)amine, and results to be a highly efficient catalyst leading to yields over $80 \%$. 


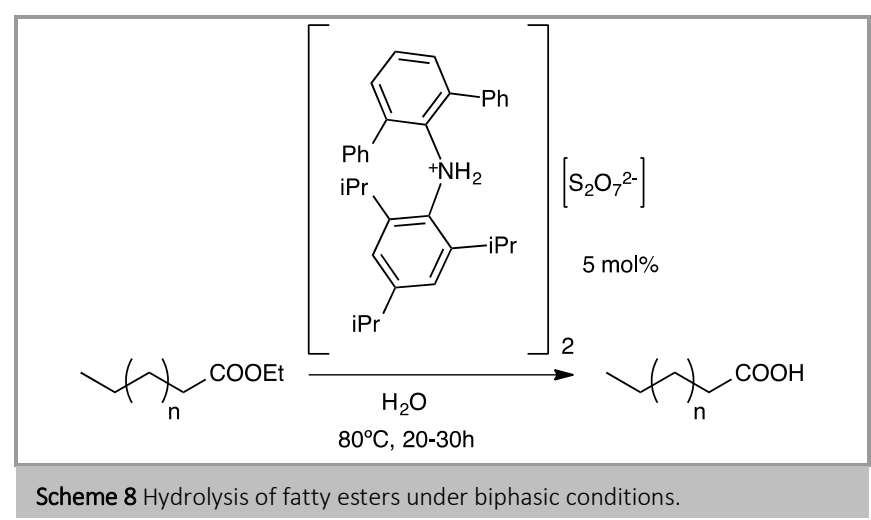

The dealkylation of fatty esters by non-hydrolytic methods has also been considered by other authors. For example, fatty acids can be obtained using two non-aqueous conditions of hydroxide-mediated ester cleavage: $\mathrm{Ba}(\mathrm{OH})_{2}$ in $\mathrm{MeOH}$, and $\mathrm{KOH}$ and 18-crown-6 in toluene; the final protonation is made with dry $\mathrm{HCl}$ in both cases and quantitative yields are obtained. ${ }^{28}$ In the case of acid- or base-sensitive substrates other strategies have been proposed. For instance, the dealkylation of methylesters can be accomplished using dimethylsulfoxonium methylide in THF with a yield above $90 \%$. Other more specific non-hydrolytic pathways for dealkylation of allylesters or homoallyesters have been described with good results. Allylesters were deprotected following a two-step procedure using $\mathrm{NaBH}_{4}$ in DMSO and then $\mathrm{HCl}^{29}$ In the case of homoallylic esters, the procedure involves a metathesis/ elimination sequence using methyl vinyl ketone with a Grubbs-Hoveyda $2^{\text {nd }}$ generation catalyst followed by addition of DBU. 30

\subsection{Synthesis of carboxylic esters}

Fatty esters can be synthesized by reaction of an alcohol with a carboxylic acid or a derivative (acid chloride or anhydride). The traditional methodology uses carboxylic acids as starting reagents since the only by-product is a molecule of water. This reaction is an equilibrium and, in order to reach high conversions, a large excess of alcohol is usually added together with a Dean-Stark water separation unit. In addition, catalytic amounts of a mineral acid are required to accelerate the reactions, such as $\mathrm{H}_{2} \mathrm{SO}_{4}$ or $\mathrm{HCl}$.

Some examples of esterification of fatty acids have been also reported using several kind of sulfonic acids as catalysts. For example, an inexpensive ultrasound-assisted synthesis of methyl and ethyl fatty esters has been reported using p-toluenesulfonic acid as catalyst. ${ }^{31}$ Yields over $80 \%$ were obtained in all cases in only 20 minutes. Other authors have described a procedure using equimolecular amounts of acids and alcohols under solvent-free and drying agent-free conditions and catalyzed by 10camphorsulfonic acid. ${ }^{32}$ Wax esters were prepared with isolated yields above $90 \%$ following this strategy.

Heterogeneous catalysis has also been applied to the esterification reaction. For instance, neopentyl glycol and ethylene glycol fatty esters were prepared in the presence of a commercial sulfonic polystyrene resin with good yields. ${ }^{33}$ Furthermore, some protic acids have been absorbed on silica gel or alumina leading to excellent yields with a great variety of alcohols. $^{34}$ Another methodology combines microwave irradiation with methanesulfonic acid immobilized onto alumina, deceasing reaction times to just a few minutes. ${ }^{35}$

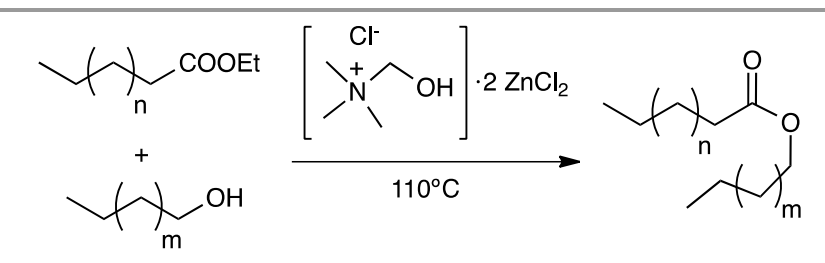

Scheme 9 Preparation of wax esters using choline chloride and $\mathrm{ZnCl}_{2}$.

There are numerous Lewis acid catalysts alternative to Brønsted acid ones for this reaction. Among the best candidates are $\mathrm{SnCl}_{2}$ or $\mathrm{SnBr}_{2}$, which are easy to handle, water tolerant, inexpensive, behave as heterogeneous catalysts and can be reused. They have been tested in the esterification of saturated and unsaturated fatty acids presenting high activity ( $>90 \%$ yield in 2 hours). ${ }^{36} \mathrm{ZnCl}_{2}$ is also able to promote the reaction to obtain wax esters using choline chloride as solvent (Scheme 9). ${ }^{37}$ Some triflate salts, such as $\mathrm{Sc}(\mathrm{OTf})_{3}$ or $\mathrm{Bi}(\mathrm{OTf})_{3},{ }^{38}$ have proven to be very efficient and in some cases chemoselective $\left(\mathrm{Zn}(\mathrm{OTf})_{2}\right)^{3}{ }^{39}$ Triflate salts are even able to promote the transesterification of fatty esters. ${ }^{38}$

Finally, a different approach has been employed for the esterification of fatty acids with sterically demanding alcohols, using $N, N^{\prime}$-dicyclohexylcarbodiimide (DCC) as coupling reagent and 4-(dimethylamino)pyridine (DMPA) as catalyst. ${ }^{40}$

\subsection{Reduction to alcohols and aldehydes}

Fatty alcohols are obtained by reduction of fatty acids or fatty alkyl esters. Among the different processes, two are the most important ones: the reduction by metal hydrides and the catalytic hydrogenolysis.

$\mathrm{LiAlH}_{4}$ is the typical reducing agent for the reduction of carboxylic acids and their derivatives to the corresponding alcohols and of course, it has been applied to fatty esters. ${ }^{41} \mathrm{NaBH}_{4}$ is a reducing agent less expensive and less moisture sensitive than $\mathrm{LiAlH}_{4}$ and is extensively used in alcoholic solvents, but carboxylic acids or esters cannot be directly reduced by $\mathrm{NaBH}_{4}$. In order to increase the reactivity of the latter, the use of additives is required. Thus, the chemoselective reduction of several fatty acids and esters can be carried out in good yields ( $>95 \%$ ) by using the system $\mathrm{HfCl}_{4} / \mathrm{NaBH}_{4}$ under mild conditions, being compatible with other functional groups. ${ }^{42}$ Yields of $90 \%$ have been also reported using the combination of the commercial phosphonitrilic chloride trimer with $\mathrm{NaBH}_{4}$ at room temperature. ${ }^{43}$ The tandem $\mathrm{CeCl}_{3}-\mathrm{NaBH}_{4}$ was also applied to the reduction of several methyl fatty esters in ethanol. ${ }^{44} \mathrm{CeCl}_{3}$ was used in $1 \mathrm{~mol} \%$ and 2 equivalents of $\mathrm{NaBH}_{4}$ were required to reach yields in the range $85-93 \%$. Also good results $(96 \%$ of yield) could be obtained using $\mathrm{I}_{2} / \mathrm{NaBH}_{4}{ }^{45}$

Other hydride sources, hydrosiloxanes, can also accomplish these reductions. This is the case of the reduction of fatty acids using the mild reducing agent tetramethyldisiloxane (TMDS) and a catalytic amount of $\mathrm{InBr}_{3}$, leading to yields of $90 \%$ (Scheme 10). ${ }^{46}$ Other authors used TMDS in combination with $\left[\mathrm{Mo}(\mathrm{O})_{2}(\mathrm{acac})_{2}\right]$ or $\left[\mathrm{V}(\mathrm{O})\left(\mathrm{O}^{\mathrm{iPr}}\right)_{3}\right]$ as catalysts, achieving quantitative conversions, ${ }^{47}$ and, in another example, the system 
$\mathrm{Cu}(\mathrm{OTf})_{2} / \mathrm{TMDS}$ yields quantitative amounts of saturated fatty alcools from their corresponding fatty acids. ${ }^{48}$

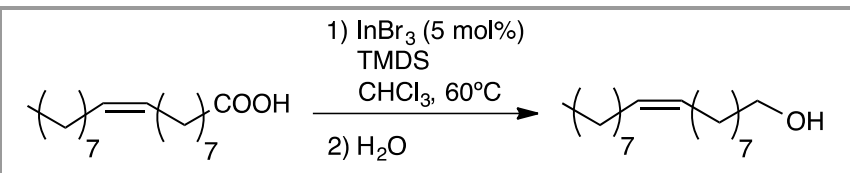

Scheme 10 Reduction of fatty acids by hydrosilylation with TMDS

As mentioned before, the catalytic hydrogenolysis involves the association of hydrogen and a metal. Industrially, the hydrogenation of fatty esters is conducted at relatively high temperatures $\left(>200^{\circ} \mathrm{C}\right)$, high hydrogen pressures ( $>200 \mathrm{bar}$ ) and using heterogeneous transition-metal catalysts, suffering from limited group tolerance. Homogeneous catalytic hydrogenation is often performed at lower temperatures and hydrogen pressure, which can lead to a higher selectivity. It is worth mentioning that, in many cases, carboxylic acids cannot be used in these homogeneous reactions since interaction with the active transition-metal center may result in catalyst deactivation. Homogeneous systems with ruthenium complexes have been recently employed for the hydrogenation of fatty esters ${ }^{26,49}$ and fatty acids ${ }^{50}$ to primary alcohols. Reaction conditions range from 40 to 70 bar $\mathrm{H}_{2}$ and from 80 to $220{ }^{\circ} \mathrm{C}$, leading to yields above $80 \%$ in all cases. Although ruthenium complexes are the most common catalysts for this reaction, other transition-metal complexes have also been reported as catalysts, for example, cobalt complexes (80 bar, $100{ }^{\circ} \mathrm{C},>75 \%$ yield $)^{14}$ or iron complexes ( 30 bar, $120{ }^{\circ} \mathrm{C}, 97 \%$ yield). 51

The preparation of aldehydes from primary alcohols through oxidative routes or from carboxylic acids or derivatives by reductive pathways is still challenging since aldehydes are usually more reactive than the starting materials, leading to chemoselectivity issues. In this regard, an interesting alternative is the direct reduction of fatty acids and derivatives to the corresponding aldehydes, which can be achieved through catalytic hydrosilylation followed by hydrolysis of the silyl groups. Very good results have been reported in the last years for the synthesis of fatty aldehydes using several commercial metal complexes, as the use of $1 \mathrm{~mol} \%$ of $\left[\mathrm{Pd}(\mathrm{dba})_{2}\right]$ for the reduction of fatty acid chlorides (68-90\% yield) ${ }^{52}$ and of fatty acids $(79 \%$ yield). ${ }^{53}$ An effective mild procedure has also been reported for the preparation of aldehydes from the hydrosilylation of fatty esters using only $0.1 \mathrm{~mol} \%$ of a commercial iridium complex (99\% yield).54 A commercially available and inexpensive manganese carbonyl complex was also used as hydrosilylation catalyst, producing fatty aldehydes with yields higher than $90 \% .55$

\subsection{Synthesis of nitrogenated derivatives}

The most commonly used process for synthesizing fatty amides at a laboratory scale is converting the carboxylic acids into more reactive derivatives, usually acyl halides using $\mathrm{SOCl}_{2}$ or oxalyl chloride, and then make them react with ammonia or amines. ${ }^{56,57}$ This kind of reaction requires very often special reaction conditions and, some reagents are moisture sensitive, corrosive, toxic and tedious work-ups for purification are necessary. Therefore, alternative methods for the direct synthesis of amides are more attractive. The cleaner direct preparation of amides from carboxylic acids and amines is a difficult task since they can form highly stable and unreactive carboxylate salts and strong heating conditions $\left(>180{ }^{\circ} \mathrm{C}\right)$ and long reaction times are required to convert that salts to the corresponding amides. In recent years, new amide preparation protocols have been developed using a catalyst for the activation of the acid. There are some examples of the application of these methodologies to the synthesis of fatty amides from fatty acids and amines or fatty amines.

Two procedures have been described for the preparation of primary amides using urea with very good results ( $>89 \%$ yield) in both cases. They are based in the use as catalysts of diammonium hydrogen orthophosphate, 58 in one case, and a commercial immobilized lipase (Novozym $\left.{ }^{\circledR} 435\right), 59$ in the other. Secondary amides could also be prepared using primary amines as reagents. The reaction of fatty acids and long-chain amines in equimolecular amounts also leads to amides, using either $\mathrm{FeCl}_{3} \cdot \mathrm{H}_{2} \mathrm{O}^{60}$ or the mesoporous silica MCM- $41^{61}$ as catalysts (7095\% yield). Other catalysts employed to obtain secondary fatty amides were $\mathrm{Mg}$ powder $(70-99 \% \text { yield })^{62}$ and $\mathrm{TiO}_{2} \quad(92 \%$ yield). 63

The direct aminolysis of fatty esters with amines is also attractive for its simplicity but frequently performs poorly in practice; nevertheless, some authors have been able to accomplish this transformation successfully by assistance of $\mathrm{Mg}\left(\mathrm{OCH}_{3}\right)_{2}$ or $\mathrm{CaCl}_{2}$ (Scheme 11).64

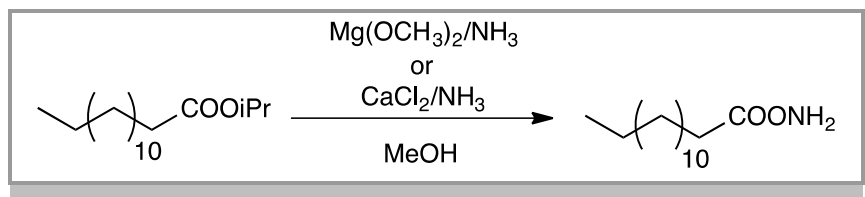

Scheme 11 Amidation of fatty esters by $\mathrm{Mg}\left(\mathrm{OCH}_{3}\right)_{3} / \mathrm{NH}_{3}$ or $\mathrm{CaCl}_{2} / \mathrm{NH}_{3}$.

The use of fatty amides as starting material for the production of amines at a laboratory scale has been the focus of recent research. In some cases, $\mathrm{LiAlH}_{4}$ has been employed as reducing agent, 65 like in the preparation of fatty alcohols, but, due to the drawbacks associate to this reagent, other routes have also been studied. For instance, hydrosilanes have become an alternative as hydride sources for the selective rutheniumcatalyzed reductive coupling of primary amides to achieve secondary amines in a one pot procedure $\left(\mathrm{PhSiH}_{3}, 53 \%\right.$ yield $) .66$ In addition, polymethylhydrosiloxane (PMHS), together with $\mathrm{Ti}\left(\mathrm{O}^{\mathrm{i} P r}\right)_{4}$, is able to provide the corresponding primary fatty amine with $90 \%$ yield. ${ }^{67}$ Another possibility to synthesize fatty secondary amines is starting from secondary amides; Thus, an elaborated procedure has been optimized for their preparation using organocerium reagents and trifluoromethanesulfonic anhydride as the activation reagent (90\% yield). ${ }^{6}$

Fatty nitriles have not direct industrial applications yet, but they are the main intermediates for the preparation of fatty amines from fatty acids or alkyl esters by reaction with $\mathrm{NH}_{3}$ at high temperature. On the other hand, at a laboratory scale, the synthesis of fatty nitriles can be a chemical transformation of interest. Significant progresses have been made in catalytic dehydration of amides to nitriles using transition metal catalysts. For instance, palladium $\left(\mathrm{PdCl}_{2}\right)$ catalyzes the dehydration of a fatty amide to nitrile with $72 \%$ yield in really mild reaction conditions. ${ }^{69}$ 
In contrast, other procedures have been developed using stoichiometric amounts of dehydrating agents. Some fatty acids can be transformed into nitriles in high yields ( $90 \%$ in $30 \mathrm{~min}$ ) by using $\mathrm{NaN}_{3}$, triethylamine, $\mathrm{PPh}_{3}$ and the commercial reagent bis(2-methoxyethyl)aminosulfur trifluoride (Deoxo-Fluor ${ }^{\circledR}$ ) (Scheme 12).70

$\underset{7}{\stackrel{C}{C O O O H} \underset{7}{\stackrel{\text { 1) } \mathrm{Et}_{3} \mathrm{~N}, \mathrm{PPh}_{3}, \mathrm{CH}_{2} \mathrm{Cl}_{2}}{\text { 2) } \mathrm{NaN}_{3}, \mathrm{DMSO}}} \text { 3) Deoxo-Fluor, } 0^{\circ} \mathrm{C}-\mathrm{rt}}$

Scheme 12 One-pot synthesis of fatty nitriles from fatty acids.

Similarly, fatty nitriles can be obtained from a fatty ester (79\% yield $)^{71}$ and some fatty acids $(70-75 \% \text { yield })^{72}$ through a one-pot procedure in three steps, using a dehydrating agent prepared in situ from diisobutylaluminium hydride (DIBAL-H). A mixture of DIBAL-H and $\mathrm{NH}_{4} \mathrm{Cl}$ was also applied to the mild transformation of fatty acids and their derivatives (esters and amides) into nitriles. ${ }^{73}$ More than $70 \%$ yield was reached in all cases, however, a significant amount of fatty amides (12-30\%) were obtained as by-products when fatty esters were used as starting materials.

\section{Oxidation of Unsaturated Fatty acids and esters}

This section will review the oxidation reactions on the hydrocarbon chain of unsaturated fatty acids and derivatives. As some reviews about different aspects of oxidation reactions of fatty acids and derivatives have been published, interested readers will be referred to them and we will here focus only in the most recent and promising results published afterwards. ${ }^{74}$

\subsection{Epoxidation and reactions of epoxides}

The epoxidation of fatty acids and fatty acid derivatives provides products with great interest not only for large-scale applications such as plasticizers or lubricants, but also for the synthesis of wide variety of compounds of high added value. Although the production of epoxidized oils reached 200,000 metric tons in 2013, the yields of the processes varied depending on the nature of the oil. Hence, new catalysts and reaction conditions are still being described in the literature with the main objective of tuning the process parameters in order to design more environmentally friendly synthesis with optimal yields and selectivity towards the desired epoxide.

Since first publications in which the use of peracids were described, different reagents have been proposed for the preparation of epoxides derived from fatty acids and fatty acid derivatives. We will briefly review the best and more recent results. Results before 2008 have already been clearly gathered in some reviews. 4,74

Several heterogeneous catalytic systems such as $\mathrm{Ti} /$ silica, $^{75,76}$ CoCuAl double layered hydroxides, ${ }^{77} \mathrm{VO}$ supported onto Indion 130,78 or $\mathrm{Mo}(\mathrm{O})_{2} \mathrm{Cl}_{2}\left(\mathrm{H}_{2}\right.$ biim $),{ }^{79}\left(\mathrm{H}_{2}\right.$ biim = 2,2'-bisimidazole $)$ supported on an ionic liquid ([BMIM] $\left.\left[\mathrm{PF}_{6}\right]\right)$ have been described as efficient systems for the epoxidation of FAMES, in connection with the use of tert-butylhydroperoxide (TBHP) as oxidant. In a typical procedure, an excess of TBHP (1.4-2 mol respect to the double bond) is used, the amount of catalyst varying between 1 and $5 \% \mathrm{~mol}$, and reaction temperature ranging from 25 to $110^{\circ} \mathrm{C}$, depending on the catalyst. Toluene, diethyl ether or acetonitrile are the preferred solvents under these conditions. Conversions over $85 \%$ are described with very good selectivities towards the epoxides. The cis epoxide is obtained as the only diastereomer in all cases. When polyunsturated fatty esters are used as starting material, as in the case of using VO-Indion 130 as catalyst, ${ }^{78}$ the diepoxide is obtained as the major product.

Finally, stereoselective epoxidation of ricinoleic has been described using $\mathrm{VO}$ (acac) 2 and TBHP as oxidant, 95:5 diastereoselectivity bein obtained (Scheme 13). ${ }^{80}$

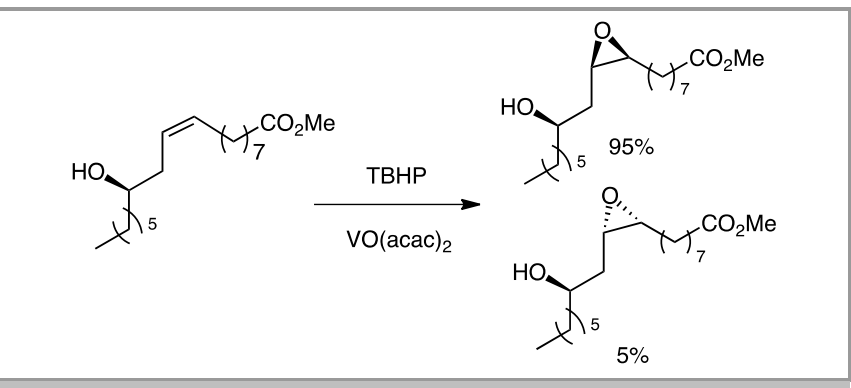

Scheme 13 Diastereoselectivity in the epoxidation of ricinoleic acid.

Nevertheless, the most used and preferred oxidant for epoxidation, both from an economic and environmental point of view, is hydrogen peroxide $\left(\mathrm{H}_{2} \mathrm{O}_{2}\right)$. It is cheap, readily available and water is the only by-product of the reaction. Epoxidation of fatty acids and esters using $\mathrm{H}_{2} \mathrm{O}_{2}$ has focused the interest in the last decade. Activation of $\mathrm{H}_{2} \mathrm{O}_{2}$ using catalytic systems is necessary in order to obtain good yields and selectivities. A great variety of homogeneous and heterogeneous catalysts have been described. We will mention here only the most promising ones. Thus, the system methyltrioxorhenium ( $4 \mathrm{~mol} \%$ ) and pyridine ${ }^{81}$ is able to fully epoxidize methyl linoleate in $4 \mathrm{~h}$. In this case, a ratio $\mathrm{H}_{2} \mathrm{O}_{2}$ /substrate of 7:1 is used. Tungsten-containing heteropolyacid catalysts provide epoxide yields up to $94 \%$ under solventfree conditions. ${ }^{82}$ Homogenous reusable systems have also been reported, ${ }^{83}$ leading to excellent yields and selectivities in the epoxidation of methyl oleate using bis[3,5-bis(trifluoromethyl)diphenyl]diselenide) in combination with fluorinated alcohols as solvents or co-solvents. Outstanding results have been obtained with heterogeneous catalysts, such as Ti-MCM41,84 alumina, ${ }^{85}$ peroxophosphotungstate immobilized onto polymeric supports ${ }^{86,87}$ or, more recently, an amphiphilic composite with magnetic $\mathrm{Fe}_{3} \mathrm{O}_{4}$ core and dodecylamine-modified polyoxometalate-paired poly(ionic liquid). ${ }^{88}$

Concerning the use of enzymes as catalysts, lipases have proven a good epoxidation activity avoiding undesired ringopening reactions. Reactions with lipases can be performed in buffer aqueous/organic mixtures or even in organic solvents. However, as the separation of the catalyst from the reaction media is not straightforward, enzyme immobilization is compulsory in order to get rid of the catalyst, and to recover it, if possible. When using fatty esters as starting materials, a certain amount of acid ( $\max 5 \%$ ) has to be added in order to form the active specie (peroxiacid) and to avoid hydrolytic activity on the ester. Excess of $\mathrm{H}_{2} \mathrm{O}_{2}$, normally 1,5-2 molar ratio, and temperature must be carefully controlled in order to obtain good results avoiding enzyme deactivation. The technological aspects 
of chemoenzymatic epoxidation of fatty acids and esters has been recently reviewed, ${ }^{89}$ so interested readers are referred to this review for detailed information.

Apart from the use of organic hydroperoxides or $\mathrm{H}_{2} \mathrm{O}_{2}$ for fatty acids epoxide synthesis, some authors have recently proposed the use of molecular oxygen as oxidant, claiming that the use of peracids involves highly exothermic reactions that causes degradation of the formed oxirane, and that the use of organic hydroperoxides or concentrated hydrogen peroxide solutions implies the storage and handling of hazardous reagents. The use of molecular oxygen, together with aldehydes as cooxidants and metal complex catalysts, has been profusely described. Unlike the case of using hydroperoxides, mixtures of cis and trans epoxides are obtained. Recently, a protocol for the in situ formation of monooxygen persulfate from inexpensive $\mathrm{Na}_{2} \mathrm{SO}_{3} / \mathrm{O}_{2}$ has been described, ${ }^{90}$ using an inorganic polyoxometalate catalyst $\left(\mathrm{H}_{5} \mathrm{PV}_{2} \mathrm{Mo}_{10} \mathrm{O}_{40}\right)$, avoiding the use of sacrificial aldehydes in the epoxidation process. The epoxidation of methyl oleate or high oleic FAMEs from different vegetable oils in a one-pot reaction over supported copper catalysts has also been reported using molecular $\mathrm{O}_{2}$ and cumene as oxygen carrier. ${ }^{91}$ With $8 \%$ of a $\mathrm{Cu}$ catalyst, supported onto alumina or onto a polymer, yields up to $87 \%$ could be obtained in a single pot at $100^{\circ} \mathrm{C}$. As mentioned above, one of the interest of the fatty acid epoxides is their easy transformation into a great variety of high valuable products (Scheme 14).

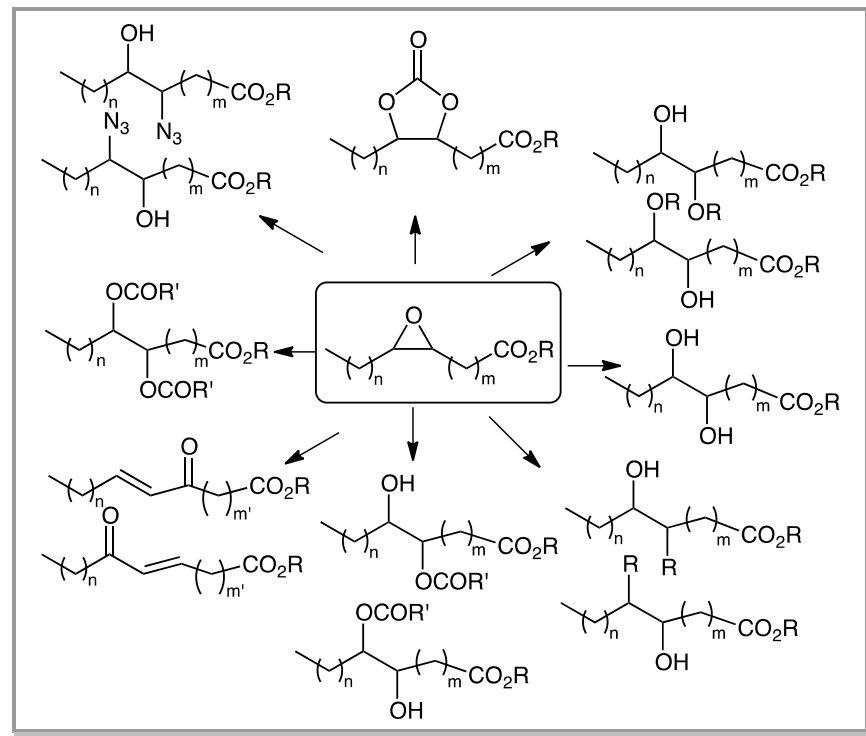

Scheme 14 Possible products coming from epoxide ring opening reactions.

For instance, diols are used as biolubricants, and as monomers for the preparation of polyesters and polyurethanes, interesting by their renewable origin and special properties. Cis dihydroxylation on unsaturated fatty acids can be accomplished through the traditional (but hardly green) synthetic method based on the use of $\mathrm{OsO}_{4}$ in ${ }^{t} \mathrm{BuOH} / \mathrm{H}_{2} \mathrm{O}$. An alternative way to obtain diols from unsaturated fatty acids, and probably the most frequently used, is the Prislezhaev method, consisting in the epoxidation and consecutive ring opening reaction using $\mathrm{HCOOH} / \mathrm{H}_{2} \mathrm{O}_{2}$ and acid media, although this method provides trans diols. A microreactor continuous flow system has been recently described for the synthesis of diols using peracetic acid as oxidant. ${ }^{92}$ With an excess of oxidant of $1.2 \mathrm{~mol}$ at $60^{\circ} \mathrm{C}, 9,10$ - dihydroxystearic acid (DHSA) was obtained in 5 min with 99\% yield. Ring opening using heterogeneous catalysts has also been proposed. The use of alumina ${ }^{93}$ or the sulfonic resin NAFION ${ }^{\circledR}$ $\mathrm{NR}^{2} 0^{94}$ is a greener alternative to the use of mineral acids such as $\mathrm{H}_{2} \mathrm{SO}_{4}$ or $\mathrm{HClO}_{4}$ for this reaction. For its easy availability, DHSA is probably the most valuable diol coming from fatty acids. A recent publication reviews the production, purification, characteristics and applications of this compound. ${ }^{95}$

Aside of diols, the ring opening of fatty epoxides derivatives with different compounds such as acids alcohols, azides, etc. provides a diversity of products with interesting properties as fuel additives, lubricants or as monomers for renewable polymers. Thus, the reaction of the epoxide of methyl oleate with organocuprates $\left(\mathrm{R}_{2} \mathrm{CuLi}\right)$ with $\mathrm{R}=$ methyl, $\mathrm{n}$-butyl, $\mathrm{n}$-hexyl or phenyl has been described for the synthesis of branched-chain hydroxyfatty acid esters. ${ }^{96}$ Both regioisomers are obtained and yields varied from 40 to $73 \%$ depending on the substituent. The ring opening reaction of the same epoxide with acids has also been described. ${ }^{97}$ Propionic, hexanoic, octanoic, 2-ehtylhexanoic and levulinic acids have been used both as reagents and reaction media. These reactions are carried out at $100{ }^{\circ} \mathrm{C}$ for $7 \mathrm{~h}$. Yields from $62 \%$ with levulinic acid to $90 \%$ with 2 -ethylhexanoic acid are described. The use of glacial acetic acid as reagent has also been described ${ }^{98}$ Conversions of $99 \%$ are achieved at $90{ }^{\circ} \mathrm{C}$ in $6 \mathrm{~h}$ reaction time. More recently, the use of magnesium stearate has been proposed as a high efficient catalyst for solvent free ringopening of methyl 9,10-epoxystearate. ${ }^{99}$ In a typical procedure, the epoxide is mixed with magnesium stearate in a 1:1 ratio, heated for $12 \mathrm{~h}$ at $160{ }^{\circ} \mathrm{C}$, leading to $99 \%$ conversion of the epoxide and $94 \%$ yield of the desired product ( 9 or) 10 -hydroxy(10 or)-9-(stearoyloxy) octadecanoic acid. This product is a grease having a great industrial potential.

When diesters are the target products, they can be readily prepared by ring opening reaction with anhydrides. For instance, the use of acetic anhydride together with several catalysts has been described for the synthesis of vicinal diacetyl esters from canola oil. ${ }^{100}$ Sulfated $\mathrm{ZrO}_{2}$ or sulfated Ti_SBA 15 provided total conversions at $130{ }^{\circ} \mathrm{C}$ using a little excess of anhydride. ${ }^{101}$ Similarly, a one-pot epoxidation of canola oil with TBHP, followed by ring opening reaction using acetic anhydride, 102 catalyzed by $10 \mathrm{wt} \% \mathrm{MoO}_{3} / \mathrm{Al}_{2} \mathrm{O}_{3}$, leads to $100 \%$ conversion to the fully $O$ acetylated products. Diesters are also available from diols. ${ }^{103}$ The synthesis of acylated derivatives is performed by esterification of diols with acetic anhydride and DMAP as catalyst. The starting diols are obtained, in turn, by the reaction of unsaturated fatty esters using the Prislezhaev method.

When opening epoxides with amines, amino alcohols are readily available. These compounds are very interesting intermediates in the synthesis of products with biological activities such as anti-HIV and antimalarian agents, among others. The synthesis of amino alcohols derived from fatty acids has been described by epoxide ring opening reactions with various aliphatic, cyclic and aromatic amines, using $\mathrm{Zn}\left(\mathrm{ClO}_{4}\right)_{2}$ as catalyst. ${ }^{104}$ Yields over $70 \%$ are obtained in all cases and all the synthesized products are fully characterized.

The epoxide ring-opening reaction with alcohols leads to fatty acid derivatives with a hydroxyl ether functionalization in the alkyl chain. This reaction is catalyzed by Brønsted and Lewis acids and examples of both options can be found in the literature. 
For instance, the ring opening reaction of isobutyl 9,10epoxystearate has been described using a number of aliphatic alcohols in the presence of $\mathrm{H}_{2} \mathrm{SO}_{4}$ in good overall yield from oleic acid. ${ }^{97}$ The use of $\mathrm{Yb}(\mathrm{OTf})_{3} . \mathrm{H}_{2} \mathrm{O}$ as catalyst has been proposed for the same reaction at $50{ }^{\circ} \mathrm{C}$ and $5 \mathrm{~h}$ reaction time, excellent yields being obtained with only $0.5 \mathrm{wt} \%$ of catalyst. ${ }^{105} \mathrm{As}$ an example of the use of heterogeneous catalysis for this reaction, $\mathrm{Nb}$ montmorillonite has been used as Brønsted acid catalyst for the synthesis of $\beta$-hydroxyethers by ring-opening of epoxidized methyl oleate with methanol. ${ }^{106}$ Finally, high yields (95\%) have been reported for the synthesis of ethers from ethyl oleate epoxide by ring opening reaction with butane-1,4-diol, catalyzed by $4 \mathrm{wt} \%$ of Amberlyst ${ }^{\circledR}$ at $70{ }^{\circ} \mathrm{C} .107$

Cyclic carbonates of oleochemical origin can be used as "green" high performance multifunctional fluids, plasticizers and precursors of polymers. Several authors have described the synthesis of these carbonates by reaction of epoxides with $\mathrm{CO}_{2}$ in the presence of a catalyst. Some of the most recent proposals include the use of simple halide salts together with phase transfer catalysts, ${ }^{108}$ ammonium halides together with polyoxometalate catalysts, ${ }^{109}$ phosphonium salts of transition metals ${ }^{110}$ or simple Lewis acids. ${ }^{111}$ In all the cases excellent yields $>95 \%$ are reported, using $\mathrm{CO}_{2}$ pressures in between 50 and 100 bar and $100{ }^{\circ} \mathrm{C}$ reaction temperature.

\subsection{Allylic oxidation}

Functionalization of the alkyl chain in a fatty acid or derivative can also be carried out by allylic oxidation reaction, although very few research has been published on this subject.

The synthesis of allylic alcohols from methyl oleate has been recently described by irradiation in the presence of a photosensitizer tetraphenylporphine (TPP) and oxygen. ${ }^{112}$ By adding triphenylphosphine, the formed allylic hydroperoxide was reduced to the allylic alcohol, which was isolated as a mixture of two regioisomers in 92\% yield (Scheme 15). The ratio of isomers is assumed to be ca. 1:1. The same authors described the synthesis of the same allylic alcohol by treatment of methyl oleate with $\mathrm{SeO}_{2}$ and TBHP. Ketoderivatives can be obtained by Wacker oxidation of internal double bonds in the alkyl chain, which consists in the oxidation with oxygen in water using palladium catalysts. Only a few examples of the synthesis of ketoderivatives of fatty acid or esters have been reported. As an example, a one-step procedure has been described for the metalfree ketonization of unsaturated fatty acid methyl esters and triacylglycerol mixtures with nitrous oxide $\left(\mathrm{N}_{2} \mathrm{O}\right) .{ }^{113}$ Temperature, reaction time and $\mathrm{N}_{2} \mathrm{O}$ partial pressure influenced the conversion of various substrates. Thus, 9- and 10-ketones were obtained from methyl oleate with very high selectivity (99\%) and complete conversion.

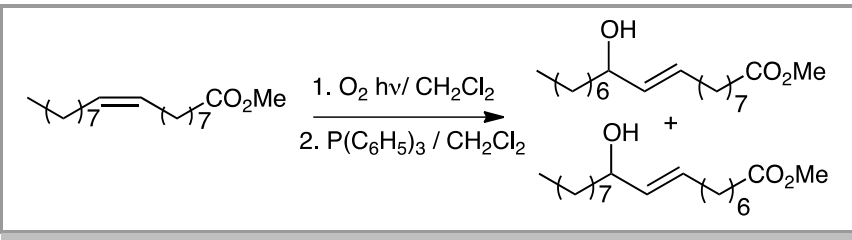

Scheme 15 Allylic oxidation of unsaturated fatty esters with dioxygen.
An efficient preparation of ketones from internal olefins has been recently reported employing $\mathrm{Pd}(\mathrm{OAc})_{2}$, benzoquinone and/or an iron co-catalyst at room temperature and at atmospheric pressure of oxygen. ${ }^{114}$ Reaction of methyl oleate provided a (1:1) mixture of 9 and 10-ketoesters in $84 \%$ yield.

Finally, an efficient and environmentally benign strategy has been described for the oxyfunctionalization of fatty acid methyl esters (FAMEs) employing oxygen as a sole re-oxidant, $\mathrm{PdCl}_{2}$ as catalyst and $\mathrm{H}_{2} \mathrm{O}$ as reaction solvent. ${ }^{115}$ Total conversions were obtained with $1-2.5 \mathrm{~mol} \%$ catalyst, at $70-75^{\circ} \mathrm{C}$ and 10 bar oxygen pressure.

\subsection{Oxidative cleavage}

Dicarboxylic acids coming from oxidative cleavage of unsaturated fatty acids or esters are of application in a wide range of industrial areas such as plastics, cosmetics, coatings, or lubricants, among others. Thus, ozonolysis has been applied at an industrial scale for the production of azelaic and pelargonic acids. Nevertheless, the safety and environmental problems of this process has encouraged the research of more suitable pathways for the synthesis of these kinds of products.

An alternative to the use of ozone has been proposed for the oxidation of oleic acid, which uses molecular oxygen over various ordered porous catalysts containing transition metal, such as $\mathrm{Cr}$, $\mathrm{Mn}$ or $\mathrm{Co}$, in supercritical carbon dioxide $\left(\mathrm{scCO}_{2}\right)$ as reaction medium. ${ }^{116}$ Conversions were always higher than $99 \%$ and product distribution strongly depended on the nature of the catalyst, reaction temperature and $\mathrm{CO}_{2}$ pressure.

Apart from this example, three different approaches have been normally envisaged for the oxidative cleavage of fatty acid derivatives (Scheme 16): direct double bond cleavage with $\mathrm{H}_{2} \mathrm{O}_{2}$ in the presence of a catalyst, a two-step reaction process starting with the dihydroxylation of the double bond and cleavage with $\mathrm{H}_{2} \mathrm{O}_{2}$, and the metathesis with ethylene and subsequent oxidation using the Wacker procedure. A great variety of catalytic systems have been described for these processes. Two reviews gathered the more relevant results until 2014.74,117 Interested readers are refered to these publications for detailed information.

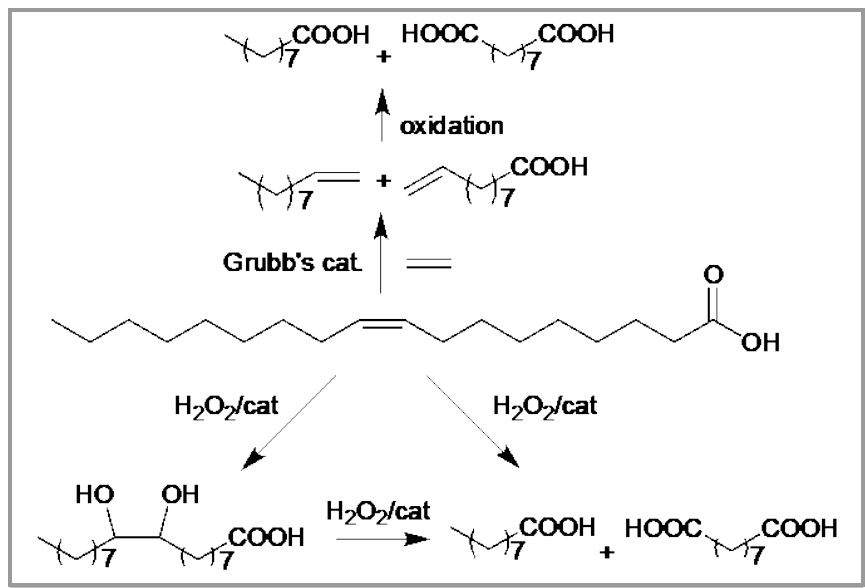

Scheme 16 Different approaches for the oxidative cleavage of unsaturated fatty acids 
Efforts in improving existing catalytic systems or in suggesting new pathways for the synthesis of dicarboxylic acids coming from renewable sources are still being done. In fact, a recent publication describes the study of the role of phasetransfer catalysts (PTC) (ammonium and phosphonium salts) with various anions on the biphasic oxidative cleavage of long chain olefins with aqueous hydrogen peroxide, catalyzed by $\mathrm{Na}_{2} \mathrm{WO}_{4} / \mathrm{H}_{3} \mathrm{PO}_{4} /$ PTC system. ${ }^{118}$

A three-step procedure has been proposed for the synthesis of aldehydes from double bond cleavage of fatty acid esters. The first step consists in an epoxidation reaction, followed by the synthesis of the $\alpha$-hydroxy ketone by an oxidative ring-opening of the epoxide and, finally, the thiazolylidene-catalyzed cleavage of the $\alpha$-hydroxy ketone derived from methyl oleate to provide the corresponding aldehydes under non-oxidative conditions, through a retro-benzoin process. ${ }^{119}$

\section{Addition reactions of unsaturated fatty acids and esters}

The same considerations made in Section 2 concerning the different reaction sites of triglycerides are valid for fatty acids and their esters of monoalcohols (Scheme 2). In particular, selectivity issues are less critical for the reactions carried out on the ester group and the $\mathrm{C}=\mathrm{C}$ double bonds, whereas reactions on allylic positions or on the isolated $\mathrm{CH}_{2}$ groups will lead to complex product mixtures in most cases.

\subsection{Hydrogenation and hydroformylation}

In spite of being the most ancient reaction performed on the hydrocarbon chain of the fatty acids/esters, there is still an active research in this field. ${ }^{120}$ The need for a selective hydrogenation of the polyunsaturated fatty acid chains from alternative sources, the requirements for trans-free mixtures, and the need for less expensive catalysts are driving forces for the research efforts.

$\mathrm{Cu} / \mathrm{SiO}_{2}(8 \% \mathrm{Cu})$ has shown to be an efficient catalyst for the selective hydrogenation of polyunsaturated fatty esters under moderate conditions $\left(2 \%\right.$ wt catalyst, $160^{\circ} \mathrm{C}, 4$ bar $\mathrm{H}_{2}, 30-120$ min), with total conversion of C18:3, decrease in C18:2 amount and sharp increase in C18:1 content (Figure 4). ${ }^{121}$ This methodology has been used for different purposes, such as the standardization of composition of fatty esters coming from vegetable oils from different sources in such a way that any of them can be used as starting material in the oleochemical industry, ${ }^{122}$ and for stabilization against oxidation of the esters mixtures from camelina oil.123 The content of polyunsaturated fatty esters from fish oil was also reduced by hydrogenation catalyzed by $\mathrm{Pd} / \mathrm{C}(10 \% \mathrm{Pd})$ under mild conditions (room temperature, 10 bar $\mathrm{H}_{2}$ ), but using a larger amount of catalyst $(10 \% \mathrm{wt})$, and the final mixture was blended with fossil diesel fuel to test its properties. ${ }^{124}$ The same type of result was obtained using a water soluble $\mathrm{Rh} / \mathrm{TPPTS}$ complex (TPPTS = sodium salt of trisulfonated triphenylphophine) in a biphasic hydrogenation process under moderate conditions $\left(120^{\circ} \mathrm{C}, 50\right.$ bar $\left.\mathrm{H}_{2}, 60 \mathrm{~min}\right)$ from mixtures of methyl fatty esters from three different vegetable oils. ${ }^{125}$

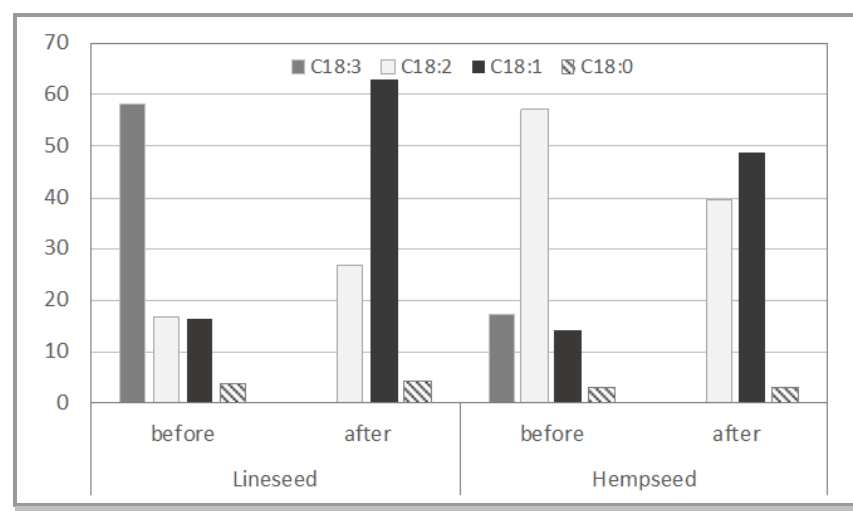

Figure 4 Composition of FAME mixtures before and after hydrogenation catalyzed by $\mathrm{Cu} / \mathrm{SiO}_{2}$

Another classical reaction for fatty acid derivatives is hydroformylation. ${ }^{126}$ This technology is considered to be mature enough to produce hydroformylated fatty esters and triglycerides, and in the last years the objectives have been focused on the recycling of the catalyst $\mathrm{t}^{127}$ and the improvement of the selectivities. ${ }^{128}$ This is probably the reason why hydroformylation is being incorporated into tandem processes with reactions such as reductive amination. The $[\mathrm{Rh}(\operatorname{cod}) \mathrm{Cl}]_{2}(2$ mol\%) catalyzed hydroformylation ( $\mathrm{CO} / \mathrm{H}_{2} 1: 1,30$ bar) of methyl oleate in methanol/decane as solvent, in the presence of proline and methanesulfonic acid (1 eq each), leads to methyl prolinate with the fatty ester as a substituent of the nitrogen (Scheme 17) with $59 \%$ yield, with recovery of the catalyst after separation of the liquid-liquid biphasic system. ${ }^{129}$

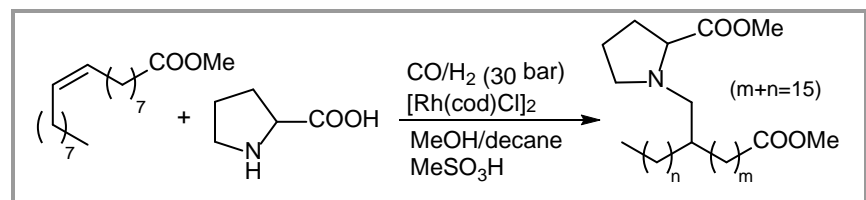

Scheme 17 Tandem hydroformylation and reductive amination of methyl oleate.

\subsection{Cycloadditions and related reactions}

In spite of the number of papers devoted to the maleinization (reaction with maleic anhydride) of fatty acid derivatives, the resulting products have been seldom characterized in-depth. Only in one case the reaction of pure conjugated triunsaturated fatty esters with maleic anhydride has been reported, with full characterization of the obtained Diels-Alder adducts, including $\mathrm{X}$-ray diffraction structures. ${ }^{130}$ In the case of methyl calendulate (C18:3 $t 8, t 10, c 12)$, the two trans $\mathrm{C}=\mathrm{C}$ bonds act as a diene in a regioselective manner and one single stereoisomer is obtained (Scheme 1). A similar behavior is observed with methyl $\alpha$ eleostearate (C18:3 $c 9, t 11, t 13)$ (Scheme 18). In the case of thermal reaction with non-conjugated polyunsaturated fatty acid derivatives, consecutive isomerization and Diels-Alder reactions were proposed, but evidences point to a different reaction pathway. 


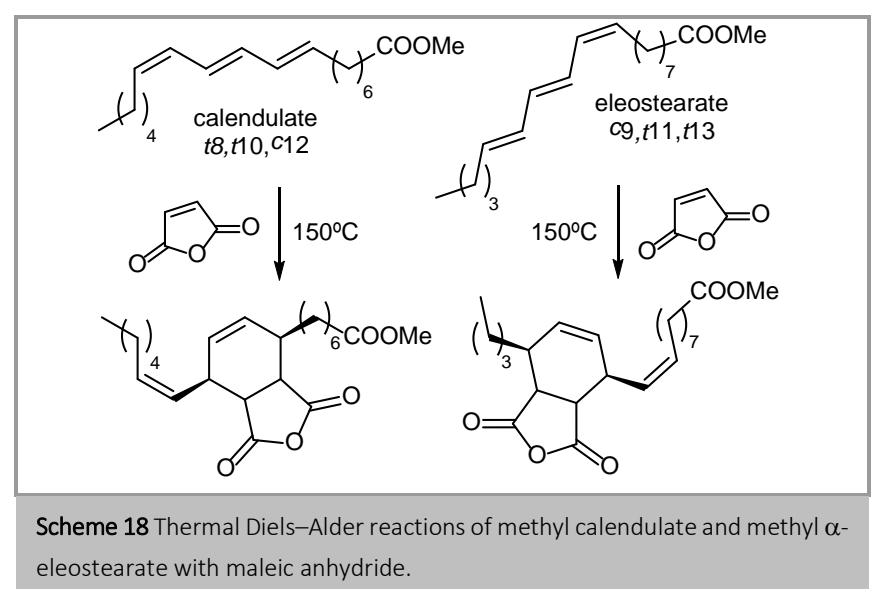

Isolated double bonds can react with maleic anhydride under thermal conditions $\left(220^{\circ} \mathrm{C}\right)$ through an ene reaction, leading to two possible regioisomers, which have not been separated.131 The existence of different reaction mechanisms, affecting to the thermal reaction of maleic anhydride with oleate or linoleate, was studied by the presence of different isomers by mass spectrometry of the reaction mixtures. ${ }^{132}$

\subsection{Addition of carboxylic acids}

The direct and selective addition of water to $\mathrm{C}=\mathrm{C}$ bonds remains challenging, and in the case of unsaturated fatty acids it has been only reached through enzymatic catalysis. ${ }^{133}$ The classic chemical method consisted in the acid-catalyzed addition of a carboxylic acid (e. g. formic acid) and then hydrolysis of the resulting ester. When the addition is carried out with the same unsaturated fatty ester, oligomers are formed which are called estolides (see Section 2.2), and they are used in different applications, such as lubricants. The oligomerization degree (estolide number) can be controlled by using a saturated fatty acid that stops the oligomerization process. The monoestolides (direct addition of the saturated fatty acid to the unsaturated one) were prepared by reaction of lauric and oleic acids (molar ratio 1:1) with $\mathrm{HClO}_{4}(0.1 \mathrm{eq})$ at $60{ }^{\circ} \mathrm{C}$ under vacuum, leading to yields in the range of $60-8 \%$ (Scheme 19). ${ }^{134}$

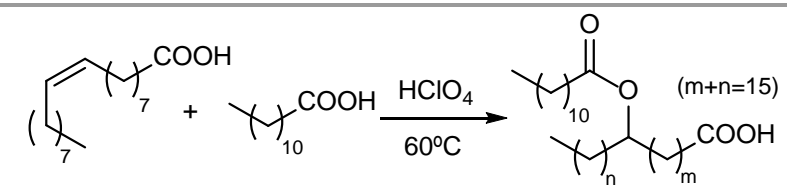

Scheme 19 Monoestolide preparation from lauric and oleic acids.

\subsection{Hydroalkylation}

The alkylation of oleic acid or its esters can be carried out using alkyl chloroformates as alkylating agents and ethylaluminum sesquichloride $\left(\mathrm{Et}_{3} \mathrm{Al}_{2} \mathrm{Cl}_{3}\right)$ as Lewis acid catalyst, with yields in the range of $70-75 \% .135$ The reaction is thought to take place through a carbenium cation generated from the alkylating agent, and hence linear primary alkyl chloroformates produce alkyation in the neighbor carbon atom due to a $1,2-\mathrm{H}$ shift (Scheme 20).

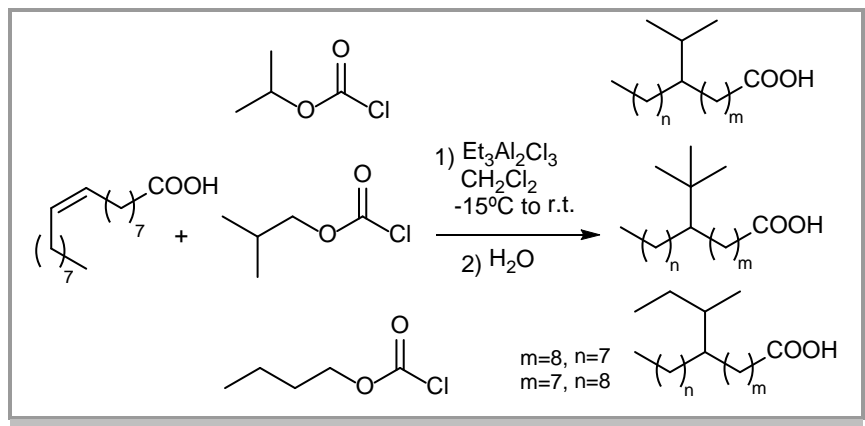

Scheme 20 Alkylation of oleic acid with alkyl chloroformates.

Branched fatty acids can alternatively obtained by reaction of methyl linoleate with propene using a double catalytic system, $\mathrm{RhCl}_{3} \cdot 3 \mathrm{H}_{2} \mathrm{O}$ and $\mathrm{Pd}\left(\mathrm{CH}_{3} \mathrm{CN}\right)_{2} \mathrm{Cl}_{2} .{ }^{136}$ The reaction takes place in an aromatic solvent at $100^{\circ} \mathrm{C}$ and 10 bar of propene with up to $81 \%$ yield (by GC). The palladium catalysts would be the responsible for the isomerization of linoleate to the conjugate diene, that then reacts with propene in a rhodium catalyzed reaction (Scheme 21). Hydrogenation of the reaction mixture with $\mathrm{Pd} / \mathrm{C}$ and $10 \mathrm{bar}$ $\mathrm{H}_{2}$ leads to a mixture of saturated branched (n-propyl substituted) stearates.

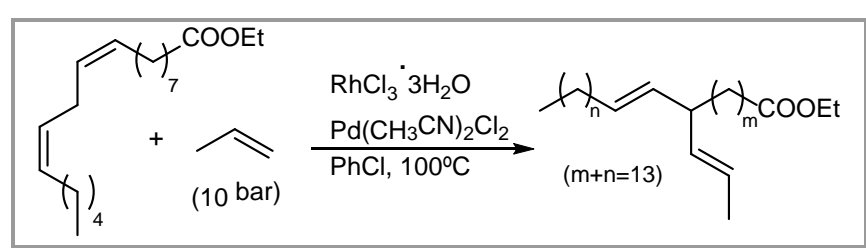

Scheme 21 Preparation of branched fatty esters by reaction of ethyl linoleate and propene.

\subsection{Radical additions}

A relatively easy way to introduce new functionalities on the hydrocarbon chain of fatty acids is the thiol-ene radical reaction, considered as an example of click-chemistry. Oleic acid, methyl oleate and triolein can react with 3 equivalents of simple thiols (docanethiol) or functionalized ones (mercaptoethanol) under UV irradiation, leading to very high yields (85-100\%) of the corresponding sulfides (Scheme 22).137

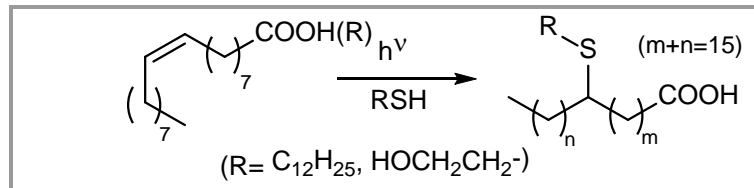

Scheme 22 Radical addition of thiols to unsaturated fatty acid derivatives.

\section{Other reactions of unsaturated fatty acids and esters}

\subsection{Cross-metathesis}

The main objective of the use of metathesis in oleochemistry ${ }^{138}$ is the preparation of $\alpha, \omega$-functionalized long hydrocarbon chains, using two distinctive strategies, selfmetathesis of the fatty acid derivative to get symmetrical molecules, or cross-metathesis with a different olefin to get a fatty acid derivative functionalized with either a terminal alkene or another group. This second strategy is much more versatile, as it allows obtaining a large variety of molecules, but it has the 
problem of self-metathesis of both reagents as side reaction and the selectivity is in general low.

The cross-metathesis of methyl oleate with (Z)-2-butene-1,4diol diacetate ( 2 eq) leads to a mixture of undec-2-enyl acetate and methyl 11-acetoxyundec-9-enoate (Scheme 23).139

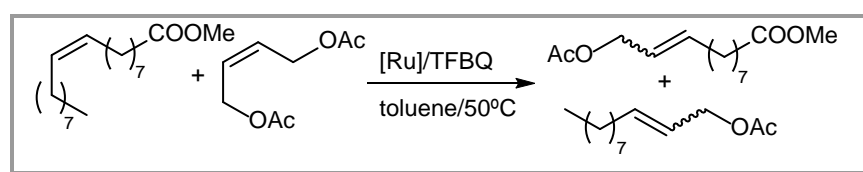

Scheme 23 Cross-metathesis with (Z)-2-butene-1,4-diol diacetate.

Several Ru catalysts ( 2 mol\%), which can be considered as variations of the second-generation Grubbs catalyst, were tested in toluene at $50{ }^{\circ} \mathrm{C}$. The results with the optimal catalyst were even improved by addition of tetrafluoro-1,4-benzoquinone, leading to $86 \%$ and $81 \%$ yield (by GC) of the two reaction products.

The precursors for nylon-11, 12 and 13 have been also prepared by cross-metathesis. In one case, methyl oleate was made react with either allyl (5 eq) or homoallyl cyanide (2.5 eq), using $2^{\text {nd }}$ generation Grubbs catalyst ( $2 \mathrm{~mol} \%$ ) and benzoquinone ( 0.5 eq) in chlorobenzene at $110{ }^{\circ} \mathrm{C} .{ }^{140}$ Isolated yields of $55 \%$ for methyl 11-cyanoundec-9-enoate and $43 \%$ for methyl 12 cyanododec-9-enoate were obtained (Scheme 24). These intermediates were hydrogenated at 20-25 bar using the same Ru catalyst and $t$-BuOK (30 mol\%) as an additive, to obtain $62 \%$ and $53 \%$ isolated yields of methyl 12 -aminododecanoate and methyl 13-aminotridecanoate, respectively.

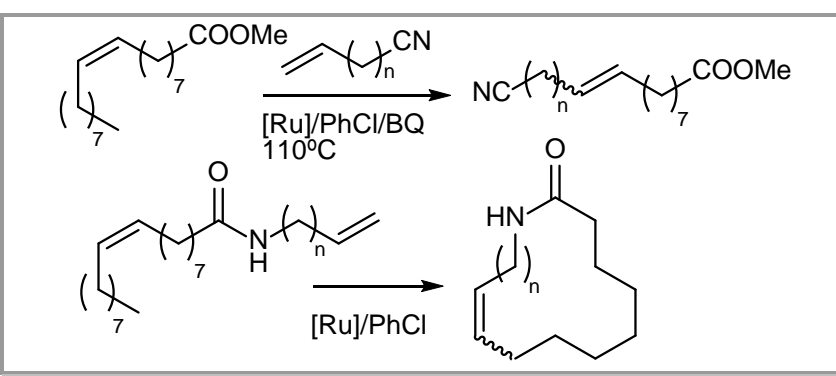

Scheme 24 Cross-metathesis for the synthesis of nylon precursors.

Another approach uses the ring-closing metathesis of $\mathrm{N}$ alkenyl oleamides. ${ }^{141}$ The amide formation ( $1^{\text {st }}$ step) was carried out from oleic acid with oxalyl choride and the hydrogenation of the unsaturated lactame ( $3^{\text {rd }}$ step) was easily obtained at $1 \mathrm{~atm}$ $\mathrm{H}_{2}$ with $\mathrm{Pd} / \mathrm{C}$. With respect to the key step, the ring-closing metathesis was carried out with Hoveyda-Grubbs $2^{\text {nd }}$ generation catalyst in chlorobenzene, but the optimal conditions and the results obtained are greatly dependent on the chain length. The best result (87\%) was obtained for 13 membered lactame (lauryl lactame), whereas the lowest yield was obtained for the 12 membered one.

\subsection{Isomerization}

Isomerization of unsaturated fatty acid derivatives may have two different objectives. On the one hand, the isomerization of linoleic acid derivatives to produce conjugated linoleic acids (CLA), ${ }^{142,143}$ due to the interesting health benefits claimed for some of the conjugated isomers (Figure 5). The classical method involves the reaction under strong basic conditions $(\mathrm{KOH})$ in an organic solvent, such as ethylene glycol, at $180{ }^{\circ} \mathrm{C}$, leading to more than $97 \%$ yield of CLA, with more than $92 \%$ yield of the two most interesting isomers, $c 9, t 11$ and $t 10, c 12$ (Figure 5). ${ }^{144}$ Metal $(\mathrm{Rh}, \mathrm{Ru})$ catalyzed isomerizations in homogeneous phase show lower productivity than the base catalyzed process, with a higher cost of the catalyst. This has been tried to overcome by using a recoverable biphasic system using an ionic liquid as solvent for the catalyst phase. ${ }^{145}$ Other possibility is to use a heterogeneous (solid) catalyst. Only recently the reported results have been comparable to those obtained with other types of catalysts, due to the synergetic effect of Ru centers and basic sites in rutheniumcontaining hydrotalcites. In that way linoleic acid (but not methyl linoleate) can be isomerized to CLA with 65\% yield in decane at $180{ }^{\circ} \mathrm{C} .146$ Iodine has been very recently described as a catalyst for the isomerization of both linoleic and linolenic acids present in sybean oil, with yields over $90 \%$ at $180{ }^{\circ} \mathrm{C} .147$<smiles>C=C/C=C\C/C=C\CC(=O)O</smiles>

Figure 5 Conjugated linoleic acids.

On the other hand, the shift of the $\mathrm{C}=\mathrm{C}$ bond of oleic acid to the terminal position of the hydrocarbon chain leads to the $\omega$ oleic acid, a source of $\alpha, \omega$-difunctionalized long chain alkanes. ${ }^{148}$ In fact, the isomerization to give the terminal double bond has not yet been described, but different metal (Ir, Rh, Pd, Ru) catalyzed addition reactions, such as hydroboration, ${ }^{149}$ hydroformylation ${ }^{150}$ or hydrocarboxylation, ${ }^{151}$ involving an isomerization in the hydride insertion step have been reported (Scheme 4), with variable activity and selectivity to the linear derivative.

As an example, 79\% yield of pure diethyl 1,2,3tricosanedioate was obtained from ethyl erucate in the Pdcatalyzed reaction $(1.6 \mathrm{~mol} \% \mathrm{Pd})$ with CO (20 bar) in ethanol at $90^{\circ} \mathrm{C}$. The corresponding diol was obtained by reduction with $\mathrm{LiAlH}_{4}$, and a mixture of diester and diol was made to polymerize to lead the polyester (Scheme 25). ${ }^{41}$

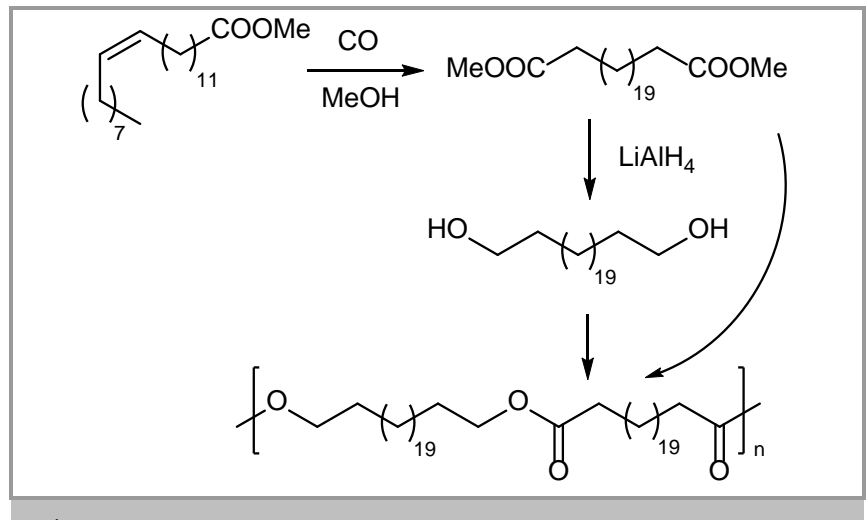

Scheme $25 \alpha, \omega$-Functionalization (hydrocarboxylation) of methyl erucate. 


\section{Conclusion and outlook}

Oleochemistry is a growing field from the industrial point of view, and one of the basis for a more sustainable chemical production, less dependent of fossil sources. In this sense, the development of selective and efficient synthetic transformations of triglycerides and fatty acids and esters is crucial for the definitive taking off of this field. Several drawbacks must be addressed, such as the intensive energy requirements of some processes (high pressures and temperatures), the difficulty of the separation and purification of the final products. Many of these drawbacks can be overcome by the use of appropriate catalytic systems. Not only catalytic processes are usually less energydemanding, but also the increase in reactivity and selectivity help to maximize the yield of the desired products, minimizing or avoiding separation steps.

Intensive research on new catalytic systems, both homogeneous and heterogeneous has been carried out in the last decade, as this short review illustrates, but more research has still to be performed to improve the synthetic procedures to lead to the target products in a way fully respectful with the principles of Green Chemistry and sustainability.

\section{Acknowledgment}

Financial support from the Spanish MINECO (project CTQ2014-52367-R), the European Social Fund (ESF) and the Gobierno de Aragón (Grupo Consolidado E11) is gratefully acknowledged.

\section{References}

(1) Besson, M.; Gallezot, P.; Pinel, C. Chem. Rev. 2014, 114, 1827.

(2) Hara, M.; Nakajima, K.; Kamata, K. Sci. Technol. Adv. Mater. 2015, 16, 34903.

(3) Gallezot, P. Chem. Soc. Rev. 2012, 41, 1538.

(4) Corma, A.; Iborra, S.; Velty, A. Chem. Rev. 2007, 107, 2411.

(5) Zhou, C.-H. C.; Beltramini, J. N.; Fan, Y.-X.; Lu, G. Q. M. Chem. Soc. Rev. 2008, 37, 527.

(6) Katryniok, B.; Kimura, H.; Skrzyńska, E.; Girardon, J.-S.; Fongarland, P.; Capron, M.; Ducoulombier, R.; Mimura, N.; Paul, S.; Dumeignil, F. Green Chem. 2011, 13, 1960.

(7) García, J. I.; García-Marín, H.; Pires, E. Green Chem. 2014, 16, 1007.

(8) Metzger, J. O. Eur. J. Lipid Sci. Technol. 2009, 111, 865.

(9) Biermann, U.; Bornscheuer, U.; Meier, M. a R.; Metzger, J. O.; Schäfer, H. J. Angew. Chem. Int. Ed. 2011, 50, 3854.

(10) Sutter, M.; Dayoub, W.; Métay, E.; Raoul, Y.; Lemaire, M. Green Chem. 2013, 15, 786

(11) Biermann, U.; Metzger, J. O. ChemSusChem 2014, 7, 644.

(12) Li, W.; Xie, J.-H.; Yuan, M.-L.; Zhou, Q.-L. Green Chem. 2014, 16, 4081.

(13) Spasyuk, D.; Smith, S.; Gusev, D. G. Angew. Chem. Int. Ed. 2012, 51 (, 2772.

(14) Korstanje, T. J.; Vlugt, J. I. van der; Elsevier, C. J.; Bruin, B. de. Science 2015, 350, 298.

(15) Ishmuratov, G. Y.; Vydrina, V. A.; Yakovleva, M. P.; Nasibullina, G. V.; Nazarov, I. S.; Muslukhov, R. R.; Tolstikov, A. G. Russ. J. Org. Chem. 2012, 48, 1509.

(16) Walther, G.; Deutsch, J.; Martin, A.; Baumann, F.-E.; Fridag, D.; Franke, R.; Köckritz, A. ChemSusChem 2011, 4, 1052.

(17) Harry-O'kuru, R. E. Lipids 2005, 40, 1179.

(18) Harry-O'kuru, R. E.; Tisserat, B.; Gordon, S. H.; Gravett, A. J. Agric. Food Chem. 2015, 63, 6588

(19) Bailosky, L. C.; Bender, L. M.; Bode, D.; Choudhery, R. A.; Craun, G. P.; Gardner, K. J.; Michalski, C. R.; Rademacher, J. T.; Stella, G. J.; Telford, D. J. Prog. Org. Coatings 2013, 76, 1712.

(20) Gandini, A.; Lacerda, T. M.; Carvalho, A. J. F. Green Chem. 2013, 15, 1514.

(21) Zhang, L.; Luo, Y.; Hou, Z.; He, Z.; Eli, W. J. Am. Oil Chem. Soc. 2013, $91,143$.

(22) Ishmuratov, G. Y.; Legostaeva, Y. V.; Botsman, L. P.; Nasibullina, G. V.; Garifullina, L. R.; Muslukhov, R. R.; Tolstikov, G. A. Russ. J. Org. Chem. 2012, 48, 1272.

(23) Ishmuratov, G. Y.; Legostaeva, Y. V.; Garifullina, L. R.; Botsman, L. P.; Idrisova, Z. I.; Muslukhov, R. R.; Ishmuratova, N. M.; Tolstikov, G. A.
Russ. J. Org. Chem. 2013, 49, 1409.

(24) Patel, J.; Elaridi, J.; Jackson, W. R.; Robinson, A. J.; Serelis, A. K.; Such, C. Chem. Commun. 2005, 5546.

(25) Patel, J.; Mujcinovic, S.; Jackson, W. R.; Robinson, A. J.; Serelis, A. K.; Such, C. Green Chem. 2006, 8, 450.

(26) Furst, M. R. L.; Goff, R. Le; Quinzler, D.; Mecking, S.; Botting, C. H.; Cole-Hamilton, D. J. Green Chem. 2012, 14, 472.

(27) Koshikari, Y.; Sakakura, A.; Ishihara, K. Org. Lett. 2012, 14, 3194.

(28) Haulotte, E.; Laurent, P.; Braekman, J.-C. Eur. J. Org. Chem. 2012 2012, 1907.

(29) Lipshutz, B. H.; Ghorai, S.; Leong, W. W. Y. J. Org. Chem. 2009, 74, 2854.

(30) Pawar, B. V.; Lokhande, P. D. Synth. Commun. 2009, 39, 2445.

(31) Pacheco, B. S.; Nunes, C. F. P.; Rockembach, C. T.; Bertelli, P.; Mesko, M. F.; Roesch-Ely, M.; Moura, S.; Pereira, C. M. P. Green Chem. Lett. Rev. 2014, 7, 265.

(32) Sakakura, A.; Koshikari, Y.; Ishihara, K. Tetrahedron Lett. 2008, 49, 5017.

(33) Jabbari, H.; Khalafy, J.; Najafi Moghadam, P. Iran. Chem. Commun. 2015, 3, 244.

(34) Chakraborti, A. K.; Singh, B.; Chankeshwara, S. V.; Patel, A. R. J. Org. Chem. 2009, 74, 5967.

(35) Fabian, L.; Gómez, M.; Caturelli Kuran, J. A.; Moltrasio, G.; Moglioni, A. Synth. Commun. 2014, 44, 2386.

(36) Ferreira, A. B.; Cardoso, A. L.; da Silva, M. J. Catal. Lett. 2013, 143, 1240.

(37) Sunitha, S.; Kanjilal, S.; Reddy, P. S.; Prasad, R. B. N. Tetrahedron Lett. 2007, 48, 6962

(38) Socha, A. M.; Sello, J. K. Org. Biomol. Chem. 2010, 8, 4753.

(39) Mamidi, N.; Manna, D. J. Org. Chem. 2013, 78, 2386.

(40) Reddy, Y. S.; Kaki, S. S.; Rao, B. B.; Jain, N.; Vijayalakshmi, P. J. Oleo Sci. 2016, 65, 81.

(41) Quinzler, D.; Mecking, S. Angew. Chem. Int. Ed. 2010, 49, 4306.

(42) Zhang, J.; Gao, X.; Zhang, C.; Ma, J.; Zhao, D. Synth. Commun. 2009, 39, 1640.

(43) Pulle, J. S.; Sagar, A. D.; Reddy, S. M.; Yadav, M. V. Pelagia Res. Libr. 2015, 6, 104.

(44) Xu, Y.; Wei, Y. Synth. Commun. 2010, 40, 3423.

(45) Pischl, M. C.; Weise, C. F.; Haseloff, S.; Müller, M.-A.; Pfaltz, A.; Schneider, C. Chem. Eur. J. 2014, 20, 17360.

(46) Sakai, N.; Kawana, K.; Ikeda, R.; Nakaike, Y.; Konakahara, T. Eur. J. Org. Chem. 2011, 3178.

(47) Pehlivan, L.; Métay, E.; Laval, S.; Dayoub, W.; Delbrayelle, D.; Mignani, G.; Lemaire, M. Eur. J. Org. Chem. 2011, 7400.

(48) Zhang, Y.-J.; Dayoub, W.; Chen, G.-R.; Lemaire, M. Tetrahedron 2012 68,7400 .

(49) Tan, X.; Wang, Y.; Liu, Y.; Wang, F.; Shi, L.; Lee, K.-H.; Lin, Z.; Lv, H.; Zhang, X. Org. Lett. 2015, 17, 454.

(50) Cui, X.; Li, Y.; Topf, C.; Junge, K.; Beller, M. Angew. Chem. Int. Ed. 2015, 54, 10596.

(51) Werkmeister, S.; Junge, K.; Wendt, B.; Alberico, E.; Jiao, H.; Baumann, W.; Junge, H.; Gallou, F.; Beller, M. Angew. Chem. Int. Ed. 2014, 53, 8722 .

(52) Fujihara, T.; Cong, C.; Iwai, T.; Terao, J.; Tsuji, Y. Synlett 2012, 23, 2389.

(53) Fujihara, T.; Cong, C.; Terao, J.; Tsuji, Y. Adv. Synth. Catal. 2013, 355, 3420 .

(54) Cheng, C.; Brookhart, M. Angew. Chem. Int. Ed. 2012, 51, 9422.

(55) Zheng, J.; Chevance, S.; Darcel, C.; Sortais, J.-B. Chem. Commun. 2013, 49, 10010

(56) Theodorou, V.; Karkatsoulis, A.; Kinigopoupou, M.; Ragoussis, V.; Skobridis, K. Arkivoc 2009, 11, 277.

(57) Mallia, V. A.; George, M.; Blair, D. L.; Weiss, R. G. Langmuir 2009, 25, 8615.

(58) Awasthi, N. P.; Singh, R. P. Eur. J. Lipid Sci. Technol. 2009, 111, 202.

(59) Awasthi, N. P.; Singh, R. P. J. Oleo Sci. 2007, 56, 507.

(60) Terada, Y.; Ieda, N.; Komura, K.; Sugi, Y. Synthesis 2008, 2318.

(61) Komura, K.; Nakano, Y.; Koketsu, M. Green Chem. 2011, 13 (4), 828.

(62) Yıldırım, A. Monatsh. Chem. 2015, 146, 947.

(63) Calcio Gaudino, E.; Carnaroglio, D.; Nunes, M. A. G.; Schmidt, L.; Flores, E. M. M.; Deiana, C.; Sakhno, Y.; Martra, G.; Cravotto, G. Catal. Sci. Technol. 2014, 4, 1395.

(64) Bundesmann, M. W.; Coffey, S. B.; Wright, S. W. Tetrahedron Lett. 2010, 51, 3879.

(65) Tinsley, J. F.; Jahnke, J. P.; Adamson, D. H.; Guo, X.; Amin, D.; Kriegel, R.; Saini, R.; Dettman, H. D.; Prud'home, R. K. Energy Fuels 2009, 23, 2065.

(66) Li, B.; Sortais, J.-B.; Darcel, C. Chem. Commun. 2013, 49, 3691.

(67) Laval, S.; Dayoub, W.; Pehlivan, L.; Métay, E.; Favre-Réguillon, A.; Delbrayelle, D.; Mignani, G.; Lemaire, M. Tetrahedron Lett. 2011, 52, 4072. 
(68) Xiao, K.-J.; Wang, A.-E.; Huang, P.-Q. Angew. Chem. Int. Ed. 2012, 51, 8314.

(69) Zhang, W.; Haskins, C. W.; Yang, Y.; Dai, M. Org. Biomol. Chem. 2014 $12,9109$.

(70) Kangani, C. O.; Day, B. W.; Kelley, D. E. Tetrahedron Lett. 2007, 48, 5933.

(71) Suzuki, Y.; Moriyama, K.; Togo, H. Tetrahedron 2011, 67, 7956

(72) Miyagi, K.; Moriyama, K.; Togo, H. Eur. J. Org. Chem. 2013, 5886.

(73) Wojtkielewicz, A.; Łotowski, Z.; Morzycki, J. Synlett 2015, 26, 2288.

(74) Köckritz, A.; Martin, A. Eur. J. Lipid Sci. Technol. 2008, 110, 812

(75) Yang, D.; Hou, M.; Ning, H.; Zhang, J.; Ma, J.; Yang, G.; Han, B. Green Chem. 2013, 15, 2261.

(76) Guidotti, M.; Psaro, R.; Ravasio, N.; Sgobba, M.; Gianotti, E.; Grinberg, S. Catal. Lett. 2007, 122, 53.

(77) Sankaranarayanan, S.; Sharma, A.; Srinivasan, K. Catal. Sci. Technol 2015, 5, 1187.

(78) Khatri, P. K.; Aila, M.; Porwal, J.; Kaul, S.; Jain, S. L. New J. Chem. 2015 $39,5960$.

(79) Neves, P.; Amarante, T. R.; Valente, A. A.; Pillinger, M.; Gonçalves, I. S. Catal. Lett. 2016, 146, 841.

(80) Davletbakova, A. M.; Baibulatova, N. Z.; Dokichev, V. A.; Muslukhov, R. R.; Yunusova, S. G.; Yunusov, M. S. Russ. J. Org. Chem. 2001, 37 1220.

(81) Du, G.; Tekin, A.; Hammond, E. G.; Wood, L. K. J. Am. Oil Chem. Soc. 2016, 81, 477.

(82) Poli, E.; Clacens, J.-M.; Barrault, J.; Pouilloux, Y. Catal. Today 2009 140, 19.

(83) De Torres, M.; Arends, I. W. C. E.; Mayoral, J. A.; Pires, E.; JimenezOses, G. Appl. Catal. A, Gen. 2012, 425, 91.

(84) Guidotti, M.; Gavrilova, E.; Galarneau, A.; Coq, B.; Psaro, R.; Ravasio, N. Green Chem. 2011, 13, 1806.

(85) Sepulveda, J.; Teixeira, S.; Schuchardt, U. Appl. Catal. A, Gen. 2007, $318,213$.

(86) Poli, E.; Bion, N.; Barrault, J.; Casciato, S.; Dubois, V.; Pouilloux, Y.; Clacens, J.-M. Catal. Today 2010, 157, 371.

(87) Poli, E.; Sousa, R. De; Jérome, F.; Pouilloux, Y.; Clacens, J.-M. Catal. Sci. Technol. 2012, 2, 910.

(88) Leng, Y.; Zhao, J.; Jiang, P.; Wang, J. ACS Appl. Mater. Interf. 2014, 6, 5947.

(89) Milchert, E.; Malarczyk, K.; Kłos, M. Molecules 2015, 20, 21481.

(90) Rubinstein, A.; Carmeli, R.; Neumann, R. Chem. Commun. 2014, 50, 13247.

(91) Scotti, N.; Ravasio, N.; Psaro, R.; Evangelisti, C.; Dworakowska, S.; Bogdal, D.; Zaccheria, F. Catal. Commun. 2015, 64, 80.

(92) van den Broek, B. A. M. W.; Becker, R.; Kössl, F.; Delville, M. M. E. Nieuwland, P. J.; Koch, K.; Rutjes, F. P. J. T. ChemSusChem 2012, 5 289.

(93) Piazza, G. J.; Nuñez, A.; Foglia, T. A. J. Am. Oil Chem. Soc. 2003, 80, 901.

(94) Usui, Y.; Sato, K.; Tanaka, M. Angew. Chem. Int. Ed. 2003, 42, 5623.

(95) Koay, G. F. L.; Chuah, T.-G.; Zainal-Abidin, S.; Ahmad, S.; Choong, T. S. Y.J. Oleo Sci. 2011, 60, 237.

(96) Dailey, O. D.; Prevost, N. T.; Strahan, G. D. J. Am. Oil Chem. Soc. 2009, $86,1101$.

(97) Moser, B. R.; Erhan, S. Z. Eur. J. Lipid Sci. Technol. 2007, 109, 206.

(98) Campanella, A.; Rustoy, E.; Baldessari, A.; Baltanás, M. A. Bioresour. Technol. 2010, 101, 245.

(99) Ahn, B.-J. K.; Kraft, S.; Sun, X. S. J. Agric. Food Chem. 2012, 60, 2179.

(100) Somidi, A. K. R.; Sharma, R. V.; Dalai, A. K. J. Am. Oil Chem. Soc. 2015, 92, 1365.

(101) Sharma, R. V.; Dalai, A. K. Appl. Catal. B, Environ. 2013, 142-143, 604.

(102) Somidi, A. K. R.; Das, U.; Dalai, A. K. Chem. Eng. J. 2016, 293, 259.

(103) Sammaiah, A.; Padmaja, K. V.; Prasad, R. B. N. J. Agric. Food Chem. 2014, 62, 4652 .

(104) Singh, S.; Kamboj, R. Ind. Eng. Chem. Res. 2010, 49, 3106.

(105) De Torres, M.; Jiménez-Osés, G.; Mayoral, J. A.; Pires, E. Bioresour. Technol. 2011, 102, 2590.

(106) Gallo, J. M. R.; Teixeira, S.; Schuchardt, U. Appl. Catal. A, Gen. 2006, 311, 199.

(107) Palaskar, D. V.; Boyer, A.; Cloutet, E.; Le Meins, J.-F.; Gadenne, B.; Alfos, C.; Farcet, C.; Cramail, H. J. Polym. Sci. A, Polymer Chem. 2012, 50,1766 .

(108) Schäffner, B.; Blug, M.; Kruse, D.; Polyakov, M.; Köckritz, A.; Martin, A.; Rajagopalan, P.; Bentrup, U.; Brückner, A.; Jung, S.; Agar, D.; Rüngeler, B.; Pfennig, A.; Müller, K.; Arlt, W.; Woldt, B.; Graß, M.; Buchholz, S. ChemSusChem 2014, 7, 1133.

(109) Langanke, J.; Greiner, L.; Leitner, W. Green Chem. 2013, 15, 1173.

(110) Tenhumberg, N.; Büttner, H.; Schäffner, B.; Kruse, D.; Blumenstein, M.; Werner, T. Green Chem. 2016, 18, 3775.

(111) Narra, N.; Rachapudi, B. N. P.; Vemulapalli, S. P. B.; Korlipara, P. V.
RSC Adv. 2016, 6, 25703.

(112) Zobel, M.; Schäfer, H. J. Eur. J. Lipid Sci. Technol. 2016, 118, 80.

(113) Hermans, I.; Janssen, K.; Moens, B.; Philippaerts, A.; Van Berlo, B. Peeters, J.; Jacobs, P. A.; Sels, B. F. Adv. Synth. Catal. 2007, 349, 1604.

(114) Morandi, B.; Wickens, Z. K.; Grubbs, R. H. Angew. Chem. Int. Ed. 2013, 52, 2944.

(115) Winkler, M.; Meier, M. a. R. Green Chem. 2014, 16, 1784.

(116) Dapurkar, S. E.; Kawanami, H.; Yokoyama, T.; Ikushima, Y. Top. Catal. 2009, 52, 707.

(117) Spannring, P.; Bruijnincx, P. C. a.; Weckhuysen, B. M.; Klein Gebbink, R. J. M. Catal. Sci. Technol. 2014, 4, 2182.

(118) Kadyrov, R.; Hackenberger, D. Top. Catal. 2014, 57, 1366.

(119) Deruer, E.; Duguet, N.; Lemaire, M. ChemSusChem 2015, 8, 2481.

(120) Philippaerts, A.; Jacobs, P. A.; Sels, B. F. Angew. Chem. Int. Ed. 2013, 52,5220 .

(121) Zaccheria, F.; Psaro, R.; Ravasio, N. Green Chem. 2009, 11, 462.

(122) Zaccheria, F.; Psaro, R.; Ravasio, N.; Bondioli, P. Eur. J. Lipid Sci. Technol. 2012, 114, 24.

(123) Pecchia, P.; Galasso, I.; Mapelli, S.; Bondioli, P.; Zaccheria, F.; Ravasio, N. Ind. Crops Prod. 2013, 51, 306.

(124) Studentschnig, A. F. H.; Schober, S.; Mittelbach, M. Energy Fuels 2015, 29, 3776

(125) Bouriazos, A.; Vasiliou, C.; Tsichla, A. Catal. Today 2015, 247, 20.

(126) Vanbésien, T.; Monflier, E.; Hapiot, F. Eur. J. Lipid Sci. Technol. 2016, $118,26$.

(127) Boulanger, J.; Ponchel, A.; Bricout, H.; Hapiot, F.; Monflier, E. Eur. J. Lipid Sci. Technol. 2012, 114, 1439.

(128) Benetskiy, E.; Lühr, S.; Vilches-Herrera, M.; Selent, D.; Jiao, H. Domke, L.; Dyballa, K.; Franke, R.; Börner, A. ACS Catal. 2014, 4, 2130.

(129) Behr, A.; Seidensticker, T.; Vorholt, A. J. Eur. J. Lipid Sci. Technol. 2014, 116, 477.

(130) Biermann, U.; Butte, W.; Eren, T.; Haase, D.; Metzger, J. O. Eur. J. Org. Chem. 2007, 3859.

(131) Candy, L.; Vaca-Garcia, C.; Borredon, E. J. Am. Oil Chem. Soc. 2005, $82,271$.

(132) Loutelier-Bourhis, C.; Zovi, O.; Lecamp, L.; Bunel, C.; Hubert-Roux, M.; Lange, C. M. Rapid Commun. Mass Spectrom. 2012, 26, 1265.

(133) Resch, V.; Hanefeld, U. Catal. Sci. Technol. 2015, 5, 1385.

(134) Cermak, S. C.; Isbell, T. A. Ind. Crops Prod. 2009, 29, 205.

(135) Biermann, U.; Metzger, J. O. J. Am. Chem. Soc. 2004, 126, 10319.

(136) Erb, B.; Dierker, M.; Ohlmann, D. M.; Gooßen, L. J. Eur. J. Lipid Sci. Technol. 2016, 118, 111.

(137) Desroches, M.; Caillol, S.; Lapinte, V.; Auvergne, R.; Boutevin, B. Macromolecules 2011, 44, 2489.

(138) Rybak, A.; Fokou, P. A.; Meier, M. A. R. Eur. J. Lipid Sci. Technol. 2008, $110,797$.

(139) Kajetanowicz, A.; Sytniczuk, A.; Grela, K. Green Chem. 2014, 16, 1579.

(140) Ameh Abel, G.; Oliver Nguyen, K.; Viamajala, S.; Varanasi, S.; Yamamoto, K. RSC Adv. 2014, 4, 55622.

(141) Yapa Mudiyanselage, A.; Viamajala, S.; Varanasi, S.; Yamamoto, K. ACS Sustain. Chem. Eng. 2014, 2, 2831.

(142) Philippaerts, A.; Goossens, S.; Jacobs, P. a.; Sels, B. F. ChemSusChem 2011, 4, 684 .

(143) Salamon, R. .; Vargáné-Visi, É.; András, C. D.; Kiss, Z. C.; Csapó, J. Acta Aliment. 2015, 44, 229.

(144) Berdeaux, O.; Voinot, L.; Angioni, E.; Juanéda, P.; Sébédio, J. L. J. Am. Oil Chem. Soc. 1998, 75, 1749.

(145) Consorti, C. S.; Aydos, G. L. P.; Ebeling, G.; Dupont, J. Appl. Catal. A, Gen. 2009, 371, 114.

(146) Chen, J.; Chen, X.; Zheng, Y.; Li, Q. RSC Adv. 2015, 5 (26), 20248.

(147) Yan, J.; Yang, J.; Yang, R.; He, H.; Liu, Q.; Lin, H. J. Serbian Chem. Soc. 2016, 81, 141.

(148) Goldbach, V.; Roesle, P.; Mecking, S. ACS Catal. 2015, 5 (10), 5951.

(149) Zhu, Y.; Jang, S. H. A.; Tham, Y. H.; Algin, O. B.; Maguire, J. A.; Hosmane, N. S. Organometallics 2012, 31, 2589.

(150) Pandey, S.; Chikkali, S. H. ChemCatChem 2015, 7, 3468.

(151) Christl, J. T.; Roesle, P.; Stempfle, F.; Wucher, P.; GöttkerSchnetmann, I.; Müller, G.; Mecking, S. Chem. Eur. J. 2013, 19, 17131. 